\title{
Connecting organic to mineral: How the physiological state of an ecosystem-engineer is linked to its habitat structure
}

\author{
Curd Amelia ${ }^{1,{ }^{*}}$, Pernet Fabrice ${ }^{2}$, Corporeau Charlotte ${ }^{2}$, Delisle Lizenn ${ }^{2}$, Firth Louise B. ${ }^{3}$, \\ Nunes Flavia ${ }^{1}$, Dubois Stanislas ${ }^{1}$
}

\author{
${ }^{1}$ IFREMER, Centre de Bretagne, DYNECO LEBCO, 29280 Plouzané, France \\ 2 IFREMER, Centre de Bretagne, LEMAR UMR 6539, 29280 Plouzané, France \\ ${ }^{3}$ School of Biological and Marine Sciences, University of Plymouth, Drake Circus, PL4 8AA Plymouth, \\ United Kingdom
}

* Corresponding author : Amelia Curd, email address : amelia.curd@ifremer.fr

\begin{abstract}
:
The honeycomb worm Sabellaria alveolata is capable of building extensive bioconstructions, including what are currently considered Europe's largest biogenic reefs. The size and volume of these bioconstructions, however, vary greatly, such that not all habitats engineered by S. alveolata may be easily identified as reefs. Given that European environmental legislation protects marine habitats that are classified as "reefs", it is important to identity a clear set of definition criteria. Furthermore, quantifiable and unequivocal criteria are also needed to evaluate the ecological (health) state of these reefs, in order to best monitor and protect them. Here we propose new terminology to describe the physical appearance of these bioconstructions and attempt to link these physical criteria to the physiological state of the tube-building polychaete. We tested whether a bioconstruction displaying outward signs of growth is built by "healthy" worms devoid of physiological stress by analysing three macromolecules (carbohydrates, proteins, lipids), four polar lipid fatty acids, six neutral lipid fatty acid markers and three metabolic enzymes (citrate synthase, catalase and superoxide dismutase). The worms were sampled in bioconstructions of different "Type" (veneer vs. hummock), "Phase" (progradation vs. retrogradation), and "Shore Level" (high shore vs. low shore) at Champeaux in MontSaint-Michel Bay, France. Our results show that worms sampled in retrograding reefs (i.e. displaying signs of erosion and colonisation by epibionts such as oysters or mussels), were less physiologically stressed than worms sampled in prograding bioconstructions, possibly due to lower intraspecific competition and hence greater food availability. We therefore suggest management measures should encompass the whole mosaic of biogenic construction Types and Phases. We propose the inclusion of the polar lipid fatty acid arachidonic acid, in combination with the activity of two metabolic enzymes, citrate synthase and superoxide dismutase, as the three key biochemical markers to consider for quantitative information on the physiological state of this particular ecosystem engineer. Our results also revealed the influence of both sex and size on fatty acid and enzyme levels, highlighting the importance of taking into account both these variables when sampling and subsequently pooling individuals by sex and size category for laboratory analyses. Once seasonal and site variation have been addressed, these biochemical indicators could be examined in parallel with S. alveolata bioconstruction physical criteria as part of a European-wide protocol for monitoring ecological status in this potential reef habitat.
\end{abstract}




\section{Graphical abstract}

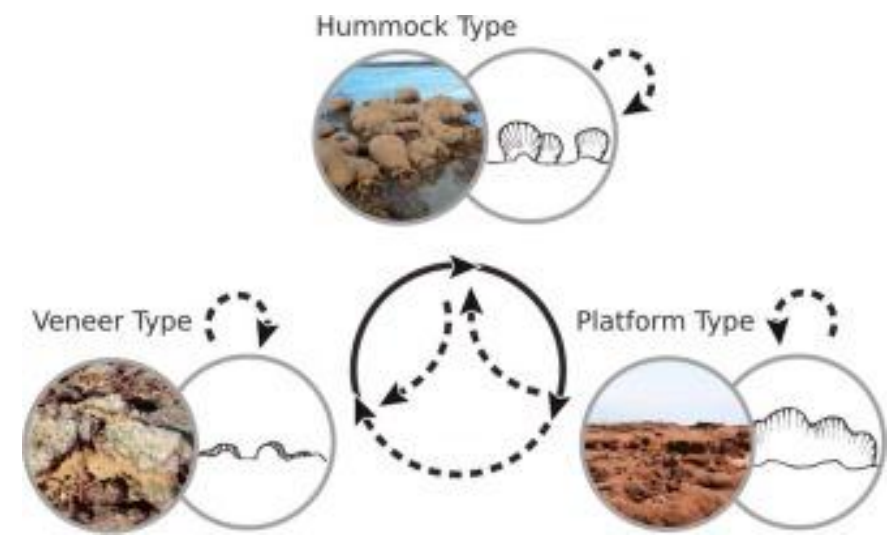

Highlights

- Biochemical markers can be informative for monitoring bioengineered habitats. Management measures should cover multiple bioconstruction types and phases. Physiological distress is not correlated with retrograding bioconstructions. Worms in retrograding bioconstructions have a higher quantity of available food. Three biochemical markers stand out as relevant physiological state descriptors.

Keywords : Biochemical indicators, Health, Ecological status, Sabellaria alveolata, Biogenic reef, Engineer species 
57 Biogenic reefs are among the most biologically diverse and functionally important habitats on

58 Earth (Goldberg, 2013). Their physical structure is known to provide numerous provisioning

59 and regulating services, such as unique habitat provision and coastal protection (Hattam et al.,

60 2015). Tropical coral reefs are often the first image that springs to mind upon hearing the term

61 "reef", and are the subject of enormous literature. Scleractinian corals, however, are only one

62 of many marine taxa capable of building biogenic reefs, which can be defined as follows:

63 "solid, massive structures which are created by accumulations of organisms" and "clearly

64 forming a substantial, discrete community or habitat which is very different from the

65 surrounding seabed" (Holt et al., 1998). In temperate waters, shellfish and tube-dwelling

66 polychaetes also fall under this definition (Bartol et al., 1999; Dubois et al., 2006). 
The term "healthy reefs" is ubiquitous throughout the literature on marine conservation; healthy reefs are often the focus of protection efforts (Abelson et al., 2017). Yet when it comes to assessing reef health status, the metrics most commonly described assess either ecological (i.e. species richness and presence of species of interest), or landscape characteristics (i.e. elevation, extent, coverage). It is unknown whether these assessments are indicative of the health of the engineering organism itself.

Reef-building sabellariid worms are ubiquitous globally in both intertidal and shallow subtidal zones. The species responsible for building what are currently considered as Europe's largest biogenic reefs (Gruet, 1986) is the honeycomb worm Sabellaria alveolata (Linnaeus, 1767). This sedentary colonial polychaete creates tubes of coarse sand grains and shell fragments cemented together; dense aggregations of which may be regarded as reefs (Holt et al., 1998). This Lusitanian species is widely distributed from southwest Scotland to Morocco where it inhabits the low- to mid-shore (Gruet, 1986; Dubois et al., 2002). As an ecosystem engineer, S. alveolata generates small to large scale topographic complexity, creating numerous spatial and trophic niches for other species to colonise (Dubois et al., 2002; 2006; Dubois and Colombo 2014; Jones et al., 2018). Their bioconstructions buffer physical and chemical stresses, protect from predators and competitors, and alter resource availability (Porras et al., 1996). Consequently, these bioconstructions host highly diverse and unique communities, composed of species originating from hard, muddy and sandy substrates, in addition to both subtidal and intertidal habitats (Dubois et al., 2002; 2006; Schimmenti et al., 2015), and are broadly considered as local hotspots of biodiversity (Jones et al., 2018).

Honeycomb worm bioconstructions constitute a highly dynamic habitat subject to numerous natural (e.g. cold winters or storms) and anthropogenic disturbances (e.g. trampling, harvesting, shellfish farming, coastal development) (Dubois et al., 2002; Firth et al. 2015; 
Plicanti et al., 2016). These bioconstructions may take on three main structural types (see e.g. Cunningham, 1984 and Holt et al., 1998, Fig. 1). Gruet (1982) described a cycle whereby a bioconstruction evolves from (1) "veneers" in which the tubes overlap and lie at an acute angle to the substratum, to (2) "hummocks" in which the tubes radiate out from the initial settlement point before reaching (3) "platforms" formed of extensive areas of hummocks fused together. In the majority of locations throughout Europe, however, neither the "hummock" nor "platform" type is ever reached. Any one of these bioconstruction types can display outward signs of being in a "progradation" or "retrogradation" phase (Figure 1a). Gruet (1982) was the first to refer to S. alveolata reef phases, which he referred to as "growth" and "destruction". Here we propose new terminology for $S$. alveolata bioconstruction development. The engineered structure is constantly in a delicate balance between these two phases, and can therefore display some or all of the characteristics listed in Figure 1 B. Patches can undergo cyclic or erratic changes whereby they prograde or retrograde either partially or totally through resettlement, as $S$. alveolata larvae, as with all sabellariid species, preferentially settle on conspecific adult tubes (Pawlik, 1986).

Currently there is no single definition or guidance of what constitutes a S. alveolata "reef". Far from being a semantic dispute, this has far-reaching implications in terms of management and conservation, as throughout the majority of its distribution (i.e. Europe) the sole legislative instrument affording any protection is the Habitats Directive (Council Directive 92/43/EEC), which only protects the "reef" form of biogenic constructions. A "reefiness" scoring system in the context of the Habitats Directive was developed by Hendrick and Foster-Smith (2006) for subtidal Sabellaria spinulosa reefs, based on a series of physical, biological and temporal characteristics weighted according to data quality of and perceived 
importance of each feature. Desroy et al. (2011) developed a Health Status Index for $S$. alveolata bioconstructions at the Bay of Mont-Saint-Michel, based on fragmentation, proportion of different bioconstruction morphological types and coverage by three key epibionts (i.e. oysters, Magallana (formerly Crassostrea) gigas, mussels, Mytilus spp., and green macroalgae, Ulva spp.). Existing rapid assessments of intertidal S. alveolata "quality" (i.e. Cunningham, 1984; Firth et al., 2015) are based on visual evaluations of the bioconstructions, and do not consider environmental characteristics of the site. Whilst all of these scoring indices are very useful, they may not easily translate beyond the species or biogeographic regions that they were developed for. Due to differences in morphology between the two species, the "reefiness" score for S. spinulosa developed by Hendrick and Foster-Smith (2006) is more helpful as a means of comparing the relative values of two different areas of $S$. spinulosa reef. The Health Status Index developed by Desroy et al. (2011) is only applicable in areas where $S$. alveolata bioconstructions reach the platform type and become colonised by M. gigas or Mytilus spp., thus restricting its application. Furthermore, not only do both of these indices require a considerable amount of field and laboratory work with numerous field experts, they also rely entirely on the physical looking-aspect of the bioconstruction. For example, muddy and fragmented bioconstruction patches have a low score on Desroy et al. (2011) health scale, disregarding the actual physiological state of the worm.. The main objective of the present study was to develop a generic tool that would be applicable across the entire geographic range of $S$. alveolata, able to help linking the physical state of the bioconstructions with the physiological state of the individuals.

Biochemical proxies may provide generic health indicators well suited for $S$. alveolata. Cell health and survival rely on a series of biochemical fluxes and reactions that are highly conserved among species and biogeographic regions (Hochachka and Somero, 2002). 
Therefore, biochemical indicators can be used as a snapshot of the physiological condition of the individual at the time it was sampled (Fraser, 1989; Dahlhoff, 2004), and could potentially have similar applicability across a variety of taxa. In order to understand how the physiological condition of S. alveolata ties in with their bioconstruction structure (i.e. type, phase and shore level), we focused on a suite of metabolic parameters that reflect several key physiological processes.

Information on the organic macromolecules of a species is fundamental to understanding its biochemical characteristics. Carbohydrates and neutral lipids constitute major energy reserves for fuelling growth, reproduction, and defence against stressors in many marine invertebrates (e.g. Gallager et al., 1986; Berthelin et al., 2000; Rivest et al., 2017). Glycogen is the primary polysaccharide (polymeric carbohydrate) in annelids (Scheer, 1969) and has long been recognised as the principal energy reserve in juvenile and adult bivalves (Lucas and Beninger, 1985). It serves both as an energy reserve under unfavourable environmental conditions, and also for the formation of gametes (Gabbott, 1975). Quantifying glycogen levels may therefore provide an indication of the level of energy reserves in S. alveolata.

Fatty acids, which are key constituents of the lipid compartment, vary with environmental factors such as temperature (e.g. Pernet et al., 2007) or salinity (Fuhrmann et al., 2018), trophic sources (Winder et al., 2017) and life history stage (e.g. Soudant et al., 1999; Lourenço et al., 2017). On one hand, the fatty acid composition of neutral lipids, which generally consists of triglycerides, reflects the fatty acid profile of the food consumed, thus revealing useful information about quality and assimilation of trophic sources (Dalsgaard, 2003). On the other hand, the fatty acid composition of polar lipids, which mainly originate from cell membranes (phospholipids), is altered to enable physiological adaptation of 
organisms to their physical environment (Hazel and Williams, 1990; Hochachka and Somero, 2002). The best example of this is the remodelling of membrane lipids by ectothermic animals, including $S$. alveolata, to counteract the effect of temperature on membrane fluidity (Hazel, 1995; Muir et al., 2016). Some fatty acids are particularly informative. The fatty acid 20:4n-6 (arachidonic acid) is a precursor of hormones involved in stressful or energetically expensive situations, namely gametogenesis and spawning (Osada, Nishikawa and Nomura, 1989), stimulation of immune functions in marine invertebrates (Delaporte, 2003) and acclimation to increasing seawater temperatures in S. alveolata (Muir et al., 2016). Therefore, fatty acid composition acts as a good stress bioindicator in marine organisms.

Metabolism is the biological processing of energy and materials through a series of biochemical reactions catalysed by enzymes (Brown et al., 2004). Metabolic enzymes are proteins which help maintain physiological homeostasis. Citrate synthase is a central enzyme in the process of sugar oxidation involved in adenosine triphosphate (ATP) generation. It is the first step of the citric acid or Krebs cycle, consisting of a series of chemical reactions which generate energy through the oxidation of acetyl-Coenzyme A derived from carbohydrates, lipids and proteins. Citrate synthase activity (CS) is correlated with respiration rate in marine invertebrates and can be used as indicator of oxidative stress (Dahlhoff et al., 2002). Reactive oxygen species (ROS) are generated through cell respiration and their production is exacerbated by environmental stressors such as contaminants, pathogens and dietary restrictions (e.g. Abele and Puntarulo, 2004 for review). Accumulation of ROS in aerobic cells can result in oxidative stress in the host (Lesser, 2006) which is normally prevented by an enzymatic antioxidant system. Studies have highlighted the importance of the enzymes superoxide dismutase (SOD) and catalase (CAT) in the prevention of tissue damage from oxidative stress in marine invertebrates (Abele and Puntarulo, 2004 for review). 
191

192

193

The overall objective of this study was to investigate the relationship between the outward structural appearance of the bioconstruction and the physiology of the resident individuals. From a practical standpoint, we tested the effect of the physical appearance of the bioconstructions in terms of their structural Type (veneer vs. hummock, but not platform due to this type being absent from the majority of locations), Phase (progradation vs. retrogradation) and shore level (high vs. low-shore) on several well-known biochemical indicators of health. Key macromolecules, enzyme activity and fatty acid composition of neutral and polar lipids may change between different bioconstruction phases of growth and deterioration and are likely to modulate the individual's response to environmental stressors.

\section{Materials and Methods}

\subsection{Study location: Champeaux Reef}

Our study took place in the Bay of Mont-Saint-Michel (north-western France), a megatidal ( $>14 \mathrm{~m})$ ecosystem with one of the highest maximum spring tidal range values in the world (Levoy et al., 2017). It is home to the largest and most extensive biogenic constructions in Europe, namely the Saint-Anne reef $\left(2.25 \mathrm{~km}^{2}\right)$ and the Champeaux reef $\left(0.29 \mathrm{~km}^{2}\right)$ (Desroy et al., 2011). The current study focused on the Champeaux reef affixed to rocky substrate in the upper intertidal zone, situated in the southeastern part of the Bay $(48.7318,01.5520$; Figure 2). The tidal amplitude in a megatidal regime implies that the water column is very well mixed. The surrounding substrate is known as "tangue", a heterolithic sediment displaying an alternate structure of sandy and silty-muddy beds which represent the deposit of each semi-diurnal tidal cycle (Tessier, 1993). 


\subsection{Sampling design}

214

Twelve patches of $S$. alveolata were sampled on the bioconstruction during low water on the $22^{\text {nd }}$ February 2016. Five individual worms were extracted from each patch of either veneer or hummock type (Table 1). For hummocks, the distinction was made between formations presenting outward signs of either progradation or retrogradation. Most treatments were well interspersed over the study area, but within $\sim 50 \mathrm{~m}$ from each other. Although we would have ideally wished to sample all shore heights and phases for all types, our study location only allowed for prograding hummocks to be sampled both on the high and low shore, whilst retrograding hummocks were only present in the eastern part of the study site (Figure 2).

Small clumps of tubes were broken off, and five females were gently extracted from their tubes for each sampling point. In addition, five males were sampled from one low-shore hummock patch located in the centre of the reef. Worms were randomly sampled within mature individuals. Maturation stage was assessed by visual examination of the extracted worms. Unspent (i.e. those that had not shed their gametes) worms are creamy white for males and purplish/rose-violet for females, while spent worms are thin-bodied brownish (see Wilson, 1971, Gruet and Lassus, 1983, Wilson, 1968 cited in Culloty et al., 2010). All sampled worms were placed in cryotubes and immediately flash frozen in liquid nitrogen in situ before they could start releasing their gametes. Samples were then long-term stored at $80^{\circ} \mathrm{C}$ until laboratory analyses.

Table 1. Summary of the sampling design. Abbreviations: nc, not considered for analysis; F, Female; M, Male.

\begin{tabular}{llllll}
\hline Bioconstruction & Shore level & Sex & Patch & Number of & Code
\end{tabular}




\begin{tabular}{lllllll}
\cline { 1 - 2 } Type & Phase & & & & individuals & \\
\cline { 1 - 1 } Hummock & Retrogradation & nc & F & 1 & 5 & HR1 \\
Hummock & Retrogradation & nc & F & 2 & 5 & HR2 \\
Hummock & Retrogradation & nc & F & 3 & 5 & HR3 \\
Hummock & Progradation & High & F & 1 & 5 & HPHs1 \\
Hummock & Progradation & High & F & 2 & 5 & HPHs2 \\
Hummock & Progradation & High & F & 3 & 5 & HPHs3 \\
Hummock & Progradation & Low & F & 1 & 5 & HPLs1 \\
Hummock & Progradation & Low & F \& M & 2 & $5 \& 3$ & HPLs2 \\
Hummock & Progradation & Low & F & 3 & 5 & HPLs3 \\
Veneer & nc & nc & F & 1 & 5 & V1 \\
Veneer & nc & nc & F & 2 & 5 & V2 \\
Veneer & nc & nc & F & 3 & 4 & V3 \\
\hline
\end{tabular}

236

237

238

239

240

\subsection{Laboratory analyses}

Individual worms were weighed and ice-cold milliQ water was added at $1 / 4$ mass volume ratio. Then, samples were grinded and homogenised $2 \times 20$ seconds at $4.5 \mathrm{~m} \mathrm{sec}^{-1}$ using the FastPrep-24TM 5G Instrument (MP Biomedicals SARL, Illkirch, France). Tissue samples were aliquoted in one tube containing $100-200 \mu \mathrm{L}$ for lipid analyses and in six tubes containing 180 $\mu \mathrm{L}$ for carbohydrate and protein extraction.

\subsubsection{Carbohydrates}

An aliquot of $180 \mu \mathrm{l}$ of tissue sample was used for determination of total carbohydrate concentrations. Briefly, samples were diluted 10 times by addition of $820 \mu \mathrm{L}$ MilliQ water. Carbohydrate concentrations were determined by colorimetric method according to DuBois (1956). Then, samples $(250 \mu \mathrm{L})$ were mixed with phenol $(0.5 \mathrm{ml}, 5 \% \mathrm{~m} / \mathrm{v})$ and sulfuric acid (2.5 ml, 98\%), and incubated for $40 \mathrm{~min}$. Absorbance was read at $490 \mathrm{~nm}$ with a UV 941 spectrophotometer (Kontron instruments, San Diego, California, USA). Carbohydrate 
concentrations were determined using a standard calibration curve and expressed as $\mathrm{mg}$ of carbohydrates per g of wet weight.

\subsubsection{Lipids}

\subsubsection{Extraction}

One aliquot tube of $180 \mu 1$ was used for determination of fatty acid profiles of neutral and polar lipids. The sample was transferred into a $6 \mathrm{~mL}$ glass vial. Lipids were extracted according to Bligh and Dyer (1959). A mixture of $\mathrm{CHCl}_{3}: \mathrm{MeOH} 1: 2(\mathrm{v} / \mathrm{v}, 750 \mu \mathrm{L})$ was added to the sample. Then, the sample was vortexed before adding pure $\mathrm{CHCl}_{3}(250 \mu \mathrm{L})$, vortexed again, diluted with MilliQ water $(250 \mu \mathrm{L})$, vortexed again, and centrifuged at $3000 \mathrm{rpm}$ for 5 minutes. The lower organic phase was transferred into another clean 2-mL glass vial. The remaining aqueous phase was washed with $500 \mu \mathrm{L} \mathrm{CHCl}_{3}$, vortexed, and centrifuged again. The lower phase was recovered, pooled with the first one and evaporated under a nitrogen flow. The sample was stored at $-20^{\circ} \mathrm{C}$ in $1 \mathrm{~mL}$ of $\mathrm{CHCl}_{3}: \mathrm{MeOH} 98: 2(\mathrm{v} / \mathrm{v})$.

\subsubsection{Neutral and Polar Lipid Separation}

Subsamples $(250 \mu \mathrm{L})$ were then placed on the top of a silica gel micro column $(30 \times 5 \mathrm{~mm}$ internal diameter; Kieselgel; 70-230 mesh (Merck, Lyon, France); previously heated to $450^{\circ} \mathrm{C}$ and deactivated with 5\% water) (Marty et al., 1992). Neutral lipids were eluted with 10 $\mathrm{ml}$ of $\mathrm{CHCl}_{3}: \mathrm{MeOH}(98: 2, \mathrm{v} / \mathrm{v})$ and the polar lipids were recovered with $15 \mathrm{ml}$ of $\mathrm{MeOH}$. A known amount of tricosanoic acid (23:0) was added to both fractions as an internal standard.

The lipid fractions were evaporated to dryness under nitrogen, re-suspended in $\mathrm{CHCl}_{3}: \mathrm{MeOH}$ 2:1 (v/v) before transesterification. 


\subsubsection{Transesterification}

271 Neutral and polar lipids were transesterified at $100^{\circ} \mathrm{C}$ for $10 \mathrm{~min}$ with $1 \mathrm{~mL}$ of boron 272 trifluoride-methanol (12\% MeOH) (Metcalfe and Schmitz, 1961). This transesterification 273 produces fatty acid methyl esters (FAME) from the fatty acid esterified at the sn-1 and sn-2 274 position of diacylphospholipids, and the sn-2 position of plasmalogen phospholipids. It also 275 produces dimethyl acetals (DMA) from the alkenyl chains at the sn-1 position of plasmalogens (Morrison and Smith, 1964). FAME and DMA were analysed in a HP6890 gas-

277 chromatography system (Hewlett-Packard) equipped with a DB-Wax capillary column $278(30 \mathrm{~m} \times 0.25 \mathrm{~mm} ; 0.25 \mu \mathrm{m}$ film thickness; Agilent technologies). Peaks were analysed by comparison with those of a standard 37 component FAME mix (Supelco® 37, Merck) together with other known FAME mixes from marine invertebrates. Each fatty acid was expressed as the peak area percentage of the total fatty acid content. Total DMA was used as 282 an indicator of the plasmalogen level.

The fatty acid trophic markers investigated in this study were the ratio of $16: 1 n-7 / 16: 0$ and $16: 4 n-1$ both of which indicate the contribution of diatoms to the diet; the ratio of $22: 6 n-$ 3/20:5n-3 which is used as an indicator of dinoflagellate contribution relative to diatoms, all of the sum of $18: 2 n-6$ and $18: 3 n-3$, which is generally considered as a marker of terrestrial inputs; the ratio of $18: 1 n-9 / 18: 1 n-7$, which is generally used as an indicator of carnivory; the ratio of polyunsaturated/saturated fatty acid (PUFA/SFA), which is an indicator of food freshness; and the sum of iso- and anteiso-branched chain fatty acids and unbranched 15:0 and 17:0, which reflects the contribution of bacteria to the organic matter. These fatty acid food web markers are routinely used in trophic ecology (Dalsgaard, 2003). The ratio of neutral to polar lipid content was also calculated, as this proxy reflects the relative 
contribution of reserve to structural lipids and is used as a nutritional condition index that is scaled to body size (Hentschel, 1998).

\subsubsection{Enzymes}

\subsubsection{Protein extraction and quantification}

Tissue samples of $150 \mu 1$ were diluted by $2 / 3$ in ice-cold lysis buffer solution and homogenized with a Polytron ${ }^{\circledR}$ PT 2500 E (Kinemetica, Luzernerstrasse, Switzerland). The buffer solution was made of $150 \mathrm{mM} \mathrm{NaCl}, 10 \mathrm{mM}$ Tris, $1 \mathrm{mM}$ EDTA, $1 \mathrm{mM}$ EGTA, $1 \%$ Triton X-100, 0.5\% Igepal, 1 tablet of complete EDTA free protease inhibitor cocktail (Roche Diagnostics, Risch-Rotkreuz, Switzerland) in $25 \mathrm{ml}$ of buffer, phosphatase inhibitor cocktail III (Merck KGaA, Darmstadt, Germany) all at pH 7.4 (Le Foll et al., 2006). Homogenates were incubated for 1 hour before being centrifuged twice at $4000 \mathrm{rpm}$ for 1 hour at $4^{\circ} \mathrm{C}$ and at $11700 \mathrm{rpm}$ for $45 \mathrm{~min}$ at $4^{\circ} \mathrm{C}$ to eliminate the lipid fraction of the samples, using GR 412 and MR22 Jouan centrifuges (Thermo Scientific, Waltham MA, USA), respectively. The resulting supernatants were aliquoted and stored at $-80^{\circ} \mathrm{C}$ until protein quantification and enzyme assays.

To determine total protein concentration, an aliquot of protein extract was diluted by $1 / 10^{\text {th }}$ and quantified according to Lowry et al. (1951) using the $D C_{\mathrm{tm}}$ protein assay kit (Bio-Rad, Hercules, California, USA). Absorbance was read at $750 \mathrm{~nm}$ and protein concentrations were determined by comparison with a calibration curve of Bovine Serum Albumin provided with the kit. Results were expressed as mg of proteins per $g$ of dry tissue weight. 


\subsubsection{Citrate Synthase}

Enzyme assays were performed in triplicate at room temperature and enzyme activities were expressed and related to the total protein concentration for each sample.

Citrate synthase activity (CS; EC 4.1.3.7) was assayed at room temperature according to Childress and Somero (1979). Protein extract (20 $\mu \mathrm{L})$ was added in wells containing an assay buffer solution $(160 \mu \mathrm{L})$ which consisted of $100 \mathrm{mM}$ Tris- $\mathrm{HCl}, 0.2 \mathrm{mM}$ acetyl-coenzyme A, $0.1 \mathrm{mM} 5,5^{\prime}$-dithio-bis-[2-nitrobenzoic] acid (DTNB). The reaction was initiated by adding oxaloacetate $(0.5 \mathrm{mM} ; 20 \mu \mathrm{L})$. Absorbance was recorded for $10 \mathrm{~min}$ at $412 \mathrm{~nm}$ using a Synergy HT microplate reader (BioTek, Winooski VT, USA). Results were expressed in mU $\mathrm{mg}^{-1}$ protein, where $1 \mathrm{U}$ is the amount of enzyme to catalyze $1 \mu$ mole of TNB per minute (using $\left.\varepsilon_{\mathrm{TNB}, 412}=13.6 \mathrm{mM}^{-1} \mathrm{~cm}-1\right)$.

\subsubsection{Superoxide Dismutase}

Total superoxide dismutase activity (SOD; EC 1.15.1.1) was determined using an assay kit (Merck KgaA, Darmstadt, Germany), following the manufacturer's instruction. Superoxide dismutase activity (SOD) was measured by adding $200 \mu \mathrm{L}$ of Water-Soluble Tetrazolium salt (WST-1) to $15 \mu \mathrm{L}$ of total protein lysates 10 times diluted, and the reaction was initiated by adding $20 \mu \mathrm{L}$ of xanthine oxidase (XO) and xanthine mix. After a 20 min incubation at $37^{\circ} \mathrm{C}$, absorbance was read at 450nm using a Synergy HT microplate reader (BioTek, Winooski VT, USA). SOD is quantified by comparing the decrease in the colour development at 450nm to a standard inhibition curve, performed using SOD from bovine erythrocytes. Results were expressed in units per $\mathrm{mg}$ of protein $(\mathrm{U} / \mathrm{mg}$ ), where $1 \mathrm{U}$ of SOD is the amount of enzyme necessary to inhibit by $50 \%$ the xanthine/XO complex formation. 


$$
\begin{aligned}
& H 0_{1}: \mu_{V=} \frac{\mu_{H R}+\mu_{H P H S}+\mu_{H P L S}}{3} \\
& H 0_{2}: \mu_{H R}=\frac{\mu_{H P H S}+\mu_{H P L S}}{2}
\end{aligned}
$$

\subsubsection{Catalase}

\subsection{Statistical analyses}

Catalase activity (CAT; EC 1.11.1.6) was assessed at room temperature following Aebi (1984). Briefly, $5 \mu \mathrm{L}$ of 10 times diluted protein supernatant were added to $195 \mu \mathrm{L}$ of hydrogen peroxide solution $(10 \mathrm{mM})$ to initiate the reaction. Absorbance was immediately recorded for every $15 \mathrm{~s}$ for 4 min using a Synergy HT microplate reader (BioTek, Winooski VT, USA). CAT is expressed in $\mathrm{U} / \mathrm{mg}$ protein where $1 \mathrm{U}$ is the amount of enzyme necessary for catalysing $1 \mu$ mole of $\mathrm{H}_{2} \mathrm{O}_{2}$ per min (using $\varepsilon \mathrm{H}_{2} \mathrm{O}_{2}, 39.4 \mathrm{mM}^{-1} \mathrm{~cm}^{-1}$ ).

Mixed design analyses of covariance (ANCOVA) were used to compare lipid, carbohydrate, and protein contents, enzyme activities and relative fatty acid concentration of the S. alveolata samples among the different bioconstruction types, phases and shore level. In the model, the random factor was the patch where the samples were taken and the covariate was individual worm mass (i.e. wet weight measures for 59 individual females). The individual worm mass did not vary with bioconstruction characteristics (ANOVA $F$-test=2.35, $p=0.148$ ) and can therefore be used as an independent factor. The categorical fixed variables were the four combinations of bioconstruction types and phases: veneer $(\mathrm{V})$, retrograding hummock $(\mathrm{HR})$ and prograding hummock located either on the high-shore (HPHs) or low-shore (HPLs). Interactions between bioconstruction characteristics and worm mass were systematically not significant and therefore omitted from the model (Table 2). When $F$-tests were significant the following a priori null hypotheses $(H 0)$ were tested using contrasts: 
$H 0_{3}: \mu_{H P H S}=\mu_{H P L S}$

356 To compare males and females, the unequal variance $T$-test was used. The normality of

357 residuals and homogeneity of variances were investigated using Box-Cox transformations

358 (Box and Cox, 1964). When necessary data were log-transformed. All statistical tests were

359 performed with SAS software (SAS 9.4, Carry NC, USA).

360 Table 2. Summary of the mixed analyses of covariance (ANCOVA) model used for 361 comparing females. $\mathrm{df}=$ degrees of freedom

Sources of variation $\quad$ df

Main-plot analysis

Bioconstruction characteristics

$$
\begin{array}{lc}
\mathrm{H}_{1} \text { : Veneer }(\mathrm{V})=\text { Hummock }(\mathrm{H}) & 1 \\
\mathrm{H}_{2} \text { : Retrograding } \mathrm{H}(\mathrm{HR})=\text { Prograding } \mathrm{H}(\mathrm{HP}) & 1 \\
\mathrm{H}_{3}: \text { HP High-shore }(\mathrm{HPHs})=\text { HP Low-shore (HPLs) } & 1
\end{array}
$$

Error a: Patch (Bioconstruction characteristics) $\quad 8$

Subplot analysis

Individual worm mass 1

Error b: Individual worm mass $\times$ Patch (Bioconstruction characteristics) $\quad 47$

$\begin{array}{lr}\text { Total } & 59\end{array}$

\section{Results}

364 We investigated the effect of bioconstruction characteristics, worm mass and sex on 16

365 different parameters grouped into four categories (Figures 3 to 6). We report that 
bioconstruction characteristics were associated with variations in three out of four indicator categories, whereas both individual mass and sex drove differences in all four categories.

\subsection{Organic macromolecules}

There was a significant relationship between the neutral:polar lipid ratio and bioconstruction characteristics (Fig. 3c), where the two bioconstruction phases contrasted significantly $\left(F_{1,8}=20.1, \mathrm{p}=0.002\right)$, with a higher neutral:polar lipid ratio found in the retrogradation phase. Individual wet weight was negatively correlated with both carbohydrate and protein concentration, and positively correlated with neutral:polar lipid ratio (Fig.3d-f). Females had a neutral:polar lipid ratio that was 5.9 times higher than males (Fig.3i), however sex had no effect on either proteins or carbohydrates (Fig.3g and h).

\subsection{Fatty acids}

\subsubsection{Polar lipids}

There was a significant effect of bioconstruction characteristics on both gadoleic (20:1n-11) and arachidonic (20:4n-6) acid after controlling for individual worm mass. Gadoleic acid varied with bioconstruction type and was significantly higher in worms sampled in hummocks than in worms from veneers $\left(F_{1,8}=12.0, \mathrm{p}=0.009\right)$ (Fig.4a). Arachidonic acid levels varied with bioconstruction phase and were significantly lower in retrograding hummocks $\left(F_{1,8}=7.8\right.$, $\mathrm{p}=0.024)$ (Fig.4b). 20:4n-6 levels were near-significantly lower on the low shore $\left(F_{1,8}=4.8\right.$, $\mathrm{p}=0.059)$ at $1.9 \%$, compared to $2.2 \%$ on the high shore. Both eicosapentaenoic acid (20:5n-3) and docosahexaenoic acid (22:6n-3) were not influenced by bioconstruction characteristics (Fig. 4c and d). 22:6n-3 was the only polar lipid fatty acid to be significantly negatively correlated with individual wet weight (Fig.4h). Sex clearly influenced levels of 20:1n-11 and 22:6n-3 content but had no effect on the other markers (Fig.4i and 1); the former is present in 
greater quantity in females than in males whereas the latter is present in greater quantity in males than in females.

\subsubsection{Neutral lipids}

Fatty acid composition in neutral lipids was not influenced by bioconstruction characteristics (Fig. 5a-f). With the exception of bacterial and carnivory markers, all neutral lipids were positively influenced by individual wet weight (Fig. $5 \mathrm{gh}$ and kl). A strong difference between male and female was observed for all trophic markers, with female worms exhibiting higher values for all markers except for carnivory, where males have 18:1n-9/18:1n-7 levels twice as high as those found in females (Fig. 5o). The 16:1n-7/16:0 ratio (Fig. 5a), which is used as a diatom tracer, was corroborated by a second diatom tracer, 16:4n-1 (File S1), whose concentration was significantly influenced by both individual wet weight and sex.

\subsection{Enzyme assays}

Citrate synthase activity (CS) was significantly affected by bioconstruction characteristics (Fig. 6a); average CS was near significantly higher in worms sampled in hummocks than in veneers $(\mathrm{p}=0.054)$, and twice as high in worms sampled in the retrogradation phase compared to the progradation phase $\left(F_{1,8}=10.1, \mathrm{p}=0.013\right)$. Although superoxide dismutase activity (SOD) was not significantly influenced by bioconstruction characteristics (Fig. 6), SOD positively correlated with CS (File $\mathrm{S} 1, \mathrm{CS}=0.95+3.17 \times \mathrm{SOD}, \mathrm{r}^{2}=0.400 \mathrm{p}<0.001$ ). Individual wet weight was negatively correlated with CS, but not with catalase activity (CAT) or SOD (Fig.6). Sex clearly influenced CS activity but had no effect on either CAT or SOD (Fig.3cfi). Mean CS was 3.8 times higher in males than in females (Fig.6c). Relationships among all variables measured in our study were represented in a principal component analysis biplot (File S1). 


\section{Discussion}

413

414

Our study revealed that a retrograding Sabellaria alveolata bioconstruction does not necessarily equate with reserve-depleted worms. Indeed, carbohydrate levels did not vary between retrograding and prograding bioconstructions, and the ratio of neutral:polar lipids was in fact higher in the retrogradation phase. Neutral lipids are essential energy reserves for sustaining early life stages and play a key role in settlement, habitat selectivity and recruitment in marine invertebrates (e.g. Tremblay et al., 2007). Also, higher levels of energetic reserves are associated with a better ability to cope with stressful situations such as pathogen resistance (Lochmiller and Deerenberg 2000, Pernet et al., 2014, Ellis et al., 2011). It is therefore likely that worms living in retrograding reefs are better equipped to face stressful situations.

We also found that levels of $20: 4 n-6$ in the polar lipids of worms sampled in the retrogradation phase were lower than in the progradation phase, unexpectedly compounding the fact that worms are more stressed in progradation phase bioconstructions. Arachidonic acid is a precursor of hormones involved in stress response and levels increase for example with increasing temperature in S. alveolata (Muir et al., 2016). These authors found that across six sampling stations spanning Scotland to Morocco, the level of 20:4n-6 was lowest in worms collected in the Bay of Mont-Saint-Michel where environmental conditions were perceived to be the most favourable (e.g. hydrodynamics and sediment supply). Indeed, this is a central population within the geographic distribution of $S$. alveolata and supports the largest living biogenic reefs in Europe. Differences in 20:4n-6 observed between the two bioconstruction phases in our study were however weak $(0.25 \%)$ compared to existing natural variability across the range (1-5\%, Muir et al., 2016). Membrane 20:4n-6 is therefore a good 
indicator of stress, as it can detect differences locally as well as across a species distribution range and is therefore applicable at several scales.

Citrate synthase activity (CS) was twice as high in worms sampled in the retrogradation phase compared to the progradation phase. The CS involved in ATP generation reflects the oxygen consumption rate of animals and has been used in community ecology to evaluate the physiological status of rocky intertidal invertebrates (Dahlhoff et al., 2002). CS varies in response to multiple variables. For example, CS in marine invertebrates increases with food availability (Dowd et al., 2013), growth rate (Garcia-Esquivel et al., 2002), maintenance costs and mitochondrial density (Moyes, 2003). Therefore, the elevated levels of CS presented here require interpretation in conjunction with other markers. In our study, the observed increase in CS in retrograding bioconstructions coincided with higher levels of stored lipid reserves, as reflected by the higher neutral:polar lipid ratio. Therefore, it may reflect a feeding-induced increase in aerobic metabolism as reported in fish larvae (Ferron and Leggett, 1994) and intertidal invertebrates (Dahlhoff, 2002). Although superoxide dismutase activity (SOD) was not significantly influenced by overall bioconstruction characteristics, SOD correlated with CS and was higher in the retrogradation phase. This also points towards worms sampled in retrograding bioconstructions having a faster metabolism, as SOD processes the ROS metabolic by-products produced through aerobic respiration (Abele and Puntarulo, 2004).

To sum up, high neutral:polar lipids, low 20:4n-6, high CS, high SOD and undepleted carbohydrates all indicate that worms sampled in retrograding bioconstructions were not stressed, but rather had either a higher quantity or quality of food source. As all trophic markers were remarkably similar between the two bioconstruction phases, worms sampled in the retrogradation phase reef probably had access to food of the same quality but in greater quantity. Intraspecific competition in a densely-populated progradation-phase bioconstruction 
is a source of physiological stress due to limited food availability (Connell, 1983).

Alternatively, retrograding bioconstructions harbour more small cracks and crevices filled with deposited sediment on top of which microphytobenthos can grow and that can be made available through resuspension processes (Dubois et al., 2007; Lefebvre et al., 2009; Jones et al., 2018). Microphytobenthos is mostly composed of benthic diatoms, which are of great dietary value, compared to phytoplankton (Miller et al., 1996).

Existing assessments of the health of biogenic habitats depend primarily on visual criteria. Certain aspects of the health of tropical coral reef polyps have made use of biochemical markers, by assessing the size of energy stores (as lipid content) as a proxy for physiological condition (Anthony, 2006) or by using CS and energy-storage lipids to see how scleractinian coral larvae respond to ocean acidification and warming (Rivest and Hoffmann 2014; Rivest et al., 2017). However, none of these studies made a link between the coral polyps and their calcareous skeleton. Attempting to join the physical appearance of a bioconstruction with the physiological status of the engineering species is surprisingly new.

Our study confirms that designating a given $S$. alveolata bioconstruction as retrograding or prograding leaves room for interpretation, as shown for coral reefs (Abelson et al., 2017). Health criteria based on the physical appearance of the bioconstruction did not yield any information on the processes regulating individuals. Yet our results show that worms present in retrogradation phase bioconstructions are in a better physiological state compared to progradation phase worms. In a recent study, Jones et al. (2018) demonstrated the ecological value of retrograding (referred to as "degraded reef") S. alveolata bioconstructions which, due to their increased micro-habitat availability, act as biodiversity and recruitment promoters and harbour more diversified food sources. S. alveolata colonies, in their role as habitats, may be of considerable value to certain species of very small animals (Wilson, 1971), with 
retrograding bioconstructions showing high numbers of associated species (Porras et al., 1996; Dubois et al., 2002; Jones et al., 2018).

Although further work is needed to address large-scale variation over time, our results suggest that $S$. alveolata sampled in retrograding bioconstructions were in fact healthier. The only signs of ecosystem distress in the retrogradation phase are value judgments about the bioconstruction appearance. Prograding bioconstructions, with their rounded shapes and crisp porches, are often considered more aesthetically appealing than silty, pitted retrograding bioconstructions. Although visual beauty correlates with ecosystem health for tropical coral reefs (Haas et al., 2015), this does not appear to be the case for other S. alveolata bioconstructions.

The majority of shorelines where S. alveolata are present host a mosaic of bioconstruction types of varying heights and surface areas. With the exception of $20: 1 n-11$, all of the examined parameters did not vary between bioconstruction types. Hummock and veneer sampling points were well interspersed and, due to the Mont-Saint-Michel's bay megatidal regime, were subjected to a homogeneous water mass. None of the biochemical parameters varied significantly between the high and low shore. Although the intertidal zone is a stressful environment (Helmuth et al., 2002; Bertness et al., 2009; Firth and Williams 2009; Firth et al., 2011), the buffering role that $S$. alveolata bioconstructions play diminishes fluctuations in temperature and humidity to the point where they are able to host a number of subtidal species (Dubois et al., 2002; Jones et al., 2018 and unpublished temperature data). It is worth mentioning that the bathymetric differences between the high and low shore sampling points were minor $(c a .1 .5 \mathrm{~m})$ compared to the tidal amplitude in the Mont-Saint-Michel (>14 m). This could explain why shore level had no effect in our sampling design. Hummocks found 
lower down the shore reach a greater height relative to sea level. However, this feature is common for $S$. alveolata bioconstructions which develop around the mid-tide level, with the bioconstructions located highest on the shore being submerged at least one hour less than the bioconstructions in the low intertidal zone. In an area experiencing a semidiurnal tide cycle, this translates as four less hours to filter-feed per lunar day, hence explaining why the largest individuals are typically found in the bioconstructions lowest down the shore.

There was a five-fold difference in individual wet weight across sampled individuals, with specimens ranging from $\sim 70$ to $\sim 350 \mathrm{mg}$. We found that energetic reserves, CS, 22:6n-3 in phospholipids and four out of six trophic markers were correlated with size. It is therefore vital to take S. alveolata individual size into consideration when analyzing biochemical variables, something that is not systematically done in marine invertebrate biochemical studies. Carbohydrate and protein concentrations diminished with individual mass whereas neutral lipids increased, reflecting a size-specific biochemical composition. All of the sampled individuals were mature and collected at the adult stage. Therefore, size may be confounded with age, and differences in biochemical composition could reflect either. Both CS and 22:6n3 decreased with increasing individual mass. Body mass and basal metabolic rates are allometrically related (Hochachka and Somero , 2002). Our results suggest that differences in respiration rate in $S$. alveolata relate to cell membrane fatty acid composition. This is consistent with Hulbert's theory of membranes as metabolic pacemakers (Hulbert et al., 2005).

We found that the neutral:polar lipid ratio and five out of six neutral lipid fatty acid trophic markers were higher in female worms, whereas 22:6n-3, the carnivory trophic marker and CS were all significantly higher in male worms. Docosahexaenoic acid (DHA - 22:6n-3) is 
abundant in spermatozoa (Masuda, 2003), and hence is the only polar lipid fatty acid significantly higher in males. Invertebrate eggs typically contain few carbohydrates and are mainly composed of energy dense proteins and lipids, hence explaining higher neutral lipid contents in females (Pernet and Jaeckle, 2004). Female worms stored four times more neutral lipids than males. The neutral lipid fatty acid composition is transferred more conservatively than the polar lipid fraction and therefore mirrors more closely that of the diet. Females containing high neutral lipid levels are more susceptible to dietary change than males which contain mostly polar lipids. This renders neutral lipid-rich female $S$. alveolata more suitable than males for representing trophic-related changes in the environment, especially when investigating diets or changes in food source composition. In order to use biochemical indicators for studying trophic interactions, it is therefore important to be able to distinguish the two sexes and to sample and analyse female $S$. alveolata.

Our study examined a one-time sampling event at a single study location. Increased spatiotemporal sampling may further clarify differences between the long-term physical changes of the bioconstruction and the short-term physiological state of the worm. In the progradation phase, S. alveolata individuals displayed biochemical stress markers. However, this may be considered as temporary stress due to, for example, momentarily lacking sufficient food. A bioconstruction can move rapidly between progradation and retrogradation phases and is therefore an inherent or "natural" fluctuation. An alternative scenario is that the worm population is physiologically stressed beyond recovery. When resilience is exceeded, the future of the bioconstruction is entirely dependent on primary or secondary settlement, thus reflecting some kind of fundamental change in underlying dynamics (Johnson, 2009). Although retrograding bioconstructions support worms in a better physiological condition, the high diversity this phase supports may have a negative effect both on adult worms through 
558 interspecific competition, and on S. alveolata larval recruitment, as epiflora can lower 559 successful recruit density due to the mechanical action of algal fronds sweeping the reef 560 surface (Dubois et al., 2006). Bioconstructions will no doubt naturally undergo a cycle of 561 progradation and retrogradation. However, when resilience is exceeded the balance between 562 these two phases is upset and may cause the system to "flip" to an alternative state (Fung et 563 al., 2011). An ecosystem's health can be defined in terms of system vigour, organisation and 564 resilience (Costanza, 1992). Whilst existing ecological studies attest to retrograding $S$. 565 alveolata bioconstruction vigour and organisation (Dubois et al., 2002; Jones et al., 2018),

566

567

568

569

570

571

572

573

574

575

576

577

578

579

580

The European Habitats Directive, and the overarching Marine Strategy Framework Directive (MSFD, 2008/56/EC) give statutory significance to the definition of a "reef". Crucially, the distinction between what is considered as "reef" and what is not, is imprecise. Which $S$. alveolata bioconstruction type, and which progradation/retrogradation phase criteria are of conservation value, are yet to be defined. This has far-reaching implications in terms of environmental management and conservation. The offset between the physical state of the bioconstruction and the physiological state of the worm makes it vital to analyse the two together, and to understand the natural history and physiology of one's study organisms when using biochemical indicators for ecological studies (Dahlhoff, 2004). Seasonal, broad-scale studies are therefore warranted to further our understanding of the link between the engineer species and the engineered habitat it creates.

\section{Conclusion}

The metabolic enzymes citrate synthase and superoxide dismutase, when analysed in conjunction with the polar lipid fatty acid 20:4n-6, serve as stress markers for the 
physiological state of S. alveolata. Once seasonal and inter-site variation have been addressed, these three biochemical indicators could be looked at in priority, in concurrence with $S$. alveolata bioconstruction physical criteria, as part of a European-wide monitoring protocol. Member states will be updating their MSFD monitoring programme and measures in the coming years and are being urged by the European Commission for a coherent and coordinated approach within and between marine regions. Although exploratory biochemical analyses time and money costs are high, they greatly diminish with subsequent routine screening of a few key indicators. Furthermore, few worm specimens are needed and their collection is substantially less destructive than the sediment core sampling typically used for obtaining biodiversity metrics. Whereas physical bioconstruction parameters are site-specific, biochemical indicators are applicable across a species range and therefore serve as large-scale, quantitative metrics, provided that sex and size are controlled for.

\section{Conflict of interest}

The authors declare that they have no conflict of interest.

\section{Acknowledgements}

The authors thank C. Quéré and V. Le Roy for technical assistance with enzyme assays and fatty acid analysis. C. Cordier, S. Androuin and M. Marzloff are gratefully acknowledged for help with the figures. AC was funded by a PhD grant from Ifremer. The authors would like to thank the two anonymous reviewers for their valuable comments and suggestions. This work was supported by the Total Foundation [Grant No. 1512215 588/F, 2015] and the French National Program EC2CO-Biohefect/Dril REEHAB [Grant No. AO2016-99 3962, 2016].

\section{References}


Aebi, H., 1984. [13] Catalase in vitro, in: Methods in Enzymology. Elsevier, pp. 121-126. https://doi.org/10.1016/S0076-6879(84)05016-3

Abele, D., Puntarulo, S., 2004. Formation of reactive species and induction of antioxidant defence systems in polar and temperate marine invertebrates and fish. Comparative Biochemistry and Physiology Part A: Molecular \& Integrative Physiology 138, 405415. https://doi.org/10.1016/j.cbpb.2004.05.013

Abelson, A., Nelson, P.A., Edgar, G.J., Shashar, N., Reed, D.C., Belmaker, J., Krause, G., Beck, M.W., Brokovich, E., France, R. and Gaines, S.D., 2016. Expanding marine protected areas to include degraded coral reefs. Conservation Biology, 30: 1182-1191. doi:10.1111/cobi.12722

Anthony, K., 2006. Enhanced energy status of corals on coastal, high-turbidity reefs. Marine Ecology Progress Series 319, 111-116. doi:10.3354/meps319111

Bartol, I.K., Mann, R., Luckenbach, M., 1999. Growth and mortality of oysters (Crassostrea virginica) on constructed intertidal reefs: effects of tidal height and substrate level. Journal of Experimental Marine Biology and Ecology 237, 157-184. https://doi.org/10.1016/S0022-0981(98)00175-0Berthelin, C., Kellner, K., Mathieu, M., 2000. Storage metabolism in the Pacific oyster (Crassostrea gigas) in relation to summer mortalities and reproductive cycle (West Coast of France). Comparative Biochemistry and Physiology Part B: Biochemistry and Molecular Biology 125, 359369. https://doi.org/10.1016/S0305-0491(99)00187-X

Bertness, M.D., Leonard, G.H., Levine, J.M., Schmidt, P.R., Ingraham, A.O., 1999. Testing the relative contribution of positive and negative interactions in rocky intertidal communities. Ecology 80, 2711-2726. https://doi.org/10.1890/00129658(1999)080[2711:TTRCOP]2.0.CO;2

Bligh, E.G., Dyer, W.J., 1959. A Rapid Method of Total Lipid Extraction and Purification. Canadian Journal of Biochemistry and Physiology 37, 911-917. https://doi.org/10.1139/o59-099

Box, G.E.P., Cox, D.R., 1964. An Analysis of Transformations. Journal of the Royal Statistical Society. Series B (Methodological) 26, 211-252.

Brown, J.H., Gillooly, J.F., Allen, A.P., Savage, V.M., West, G.B., 2004. Toward a Metabolic Theory of Ecology. Ecology 85, 1771-1789. https://doi.org/10.1890/03-9000

Childress, J.J., Somero, G.N., 1979. Depth-related enzymic activities in muscle, brain and heart of deep-living pelagic marine teleosts. Marine Biology 52, 273-283. https://doi.org/10.1007/BF00398141

Connell, J.H., 1983. On the Prevalence and Relative Importance of Interspecific Competition: Evidence from Field Experiments. The American Naturalist 122, 661-696. https://doi.org/10.1086/284165

Costanza, R., 1992. Towards an operational definition of ecosystem health, in: Ecosystem Health: New Goals for Environmental Management. Island Press, pp. 239-256.

Culloty, S.C., Favier, E., Ní Riada, M., Ramsay, N.F., O’Riordan, R.M., 2010. Reproduction of the biogenic reef-forming honeycomb worm Sabellaria alveolata in Ireland. Journal of the Marine Biological Association of the United Kingdom 90, 503. https://doi.org/10.1017/S0025315409990932 
Cunningham, P.N., 1984. The geographical distribution of Sabellaria alveolata (L.) in England, Wales and Scotland, with investigations into the community structure of, and the effects of trampling on Sabellaria alveolata colonies. (N.C.C. Contract No. HF3/11/22.).

Dalsgaard J., St. John, M., Kattner, G., Muller-Navarra, D., Hagen, W., 2003. Fatty acid trophic markers in the pelagic marine environment. Advances in Marine Biology 46:225-340. doi: 10.1016/S0065-2881(03)46005-7

Dahlhoff, E.P., Stillman, J.H., Menge, B.A., 2002. Physiological community ecology: variation in metabolic activity of ecologically important rocky intertidal invertebrates along environmental gradients. Integrative and comparative biology 42, 862-871.

Dahlhoff, E.P., 2004. Biochemical Indicators of Stress and Metabolism: Applications for Marine Ecological Studies. Annual Review of Physiology 66, 183-207. https://doi.org/10.1146/annurev.physiol.66.032102.114509

Delaporte, M., 2003. Effect of a mono-specific algal diet on immune functions in two bivalve species - Crassostrea gigas and Ruditapes philippinarum. Journal of Experimental Biology 206, 3053-3064. https://doi.org/10.1242/jeb.00518

Desroy, N., Dubois, S.F., Fournier, J., Ricquiers, L., Le Mao, P., Guerin, L., Gerla, D., Rougerie, M., Legendre, A., 2011. The conservation status of Sabellaria alveolata (L.) (Polychaeta: Sabellariidae) reefs in the Bay of Mont-Saint-Michel. Aquatic Conservation: Marine and Freshwater Ecosystems 21, 462-471. doi:10.1002/aqc.1206

Dowd, W.W., Felton, C.A., Heymann, H.M., Kost, L.E., Somero, G.N., 2013. Food availability, more than body temperature, drives correlated shifts in ATP-generating and antioxidant enzyme capacities in a population of intertidal mussels (Mytilus californianus). Journal of Experimental Marine Biology and Ecology 449, 171-185.

Dubois, S., Retière, C., Olivier, F., 2002. Biodiversity associated with Sabellaria alveolata (Polychaeta: Sabellariidae) reefs: effects of human disturbances. Journal of the Marine Biological Association of the UK 82, 817-826. doi:10.1017/S0025315402006185

Dubois, S., Commito, J.A., Olivier, F., Retière, C., 2006. Effects of epibionts on Sabellaria alveolata (L.) biogenic reefs and their associated fauna in the Bay of Mont SaintMichel. Estuarine, Coastal and Shelf Science 68, 635-646. https://doi.org/10.1016/j.ecss.2006.03.010

Dubois, S., Orvain, F., Marin-Léal, J., Ropert, M., Lefebvre, S., 2007. Small-scale spatial variability of food partitioning between cultivated oysters and associated suspensionfeeding species, as revealed by stable isotopes. Marine Ecology Progress Series 336, 151-160. https://doi.org/10.3354/meps336151

Dubois, S.F., Colombo, F., 2014. How picky can you be? Temporal variations in trophic niches of co-occurring suspension-feeding species. Food Webs 1, 1-9. https://doi.org/10.1016/j.fooweb.2014.07.001

DuBois, M., Gilles, K.A., Hamilton, J.K., Rebers, P.A., Smith, F., 1956. Colorimetric Method for Determination of Sugars and Related Substances. Analytical Chemistry 28, 350356. https://doi.org/10.1021/ac60111a017 
Ellis, R.P., Parry, H., Spicer, J.I., Hutchinson, T.H., Pipe, R.K., Widdicombe, S., 2011. Immunological function in marine invertebrates: Responses to environmental perturbation. Fish \& Shellfish Immunology 30, 1209-1222. https://doi.org/10.1016/j.fsi.2011.03.017

Ferron, A., Leggett, W.C., 1994. An Appraisal of Condition Measures for Marine Fish Larvae, in: Advances in Marine Biology. Elsevier, pp. 217-303. https://doi.org/10.1016/S0065-2881(08)60064-4

Firth, L.B., Williams, G.A., 2009. The influence of multiple environmental stressors on the limpet Cellana toreuma during the summer monsoon season in Hong Kong. Journal of Experimental Marine Biology and Ecology 375, 70-75. https://doi.org/10.1016/j.jembe.2009.05.011

Firth, L.B., Knights, A.M., Bell, S.S., 2011. Air temperature and winter mortality: Implications for the persistence of the invasive mussel, Perna viridis in the intertidal zone of the south-eastern United States. Journal of Experimental Marine Biology and Ecology 400, 250-256. https://doi.org/10.1016/j.jembe.2011.02.007

Firth, L.B., Mieszkowska, N., Grant, L.M., Bush, L.E., Davies, A.J., Frost, M.T., Moschella, P.S., Burrows, M.T., Cunningham, P.N., Dye, S.R., Hawkins, S.J., 2015. Historical comparisons reveal multiple drivers of decadal change of an ecosystem engineer at the range edge. Ecology and Evolution 5, 3210-3222. https://doi.org/10.1002/ece3.1556Fraser, A.J., 1989. Triacylglycerol Content as a Condition Index for Fish, Bivalve, and Crustacean Larvae. Canadian Journal of Fisheries and Aquatic Sciences 46, 1868-1873. https://doi.org/10.1139/f89-235

Fuhrmann, M., Delisle, L., Petton, B., Corporeau, C., Pernet, F., 2018. Metabolism of the Pacific oyster, Crassostrea gigas, is influenced by salinity and modulates survival to the Ostreid herpesvirus OsHV-1. Biology Open 7, bio028134. https://doi.org/10.1242/bio.028134

Fung, T., Seymour, R.M., Johnson, C.R., 2011. Alternative stable states and phase shifts in coral reefs under anthropogenic stress. Ecology 92, 967-982. https://doi.org/10.1890/10-0378.1

Gabbott, P.A., 1975. Storage cycles in marine bivalve molluscs: a hypothesis concerning the relationship between glycogen metabolism and gametogenesis. Presented at the Ninth European Marine Biology Symposium, Aberdeen University Press, Oban, pp. 191-211.

Gallager, S.M., Mann, R., Sasaki, G.C., 1986. Lipid as an index of growth and viability in three species of bivalve larvae. Aquaculture 56, 81-103. https://doi.org/10.1016/0044$\underline{8486(86) 90020-7}$

Garcia-Esquivel, Z., Bricelj, V.M., Felbeck, H., 2002. Metabolic depression and whole-body response to enforced starvation by Crassostrea gigas postlarvae. Comparative Biochemistry and Physiology Part A: Molecular \& Integrative Physiology 133, 63-77.

Goldberg, W.M., 2013. The biology of reefs and reef organisms. University of Chicago Press, Chicago. 
Gruet, Y., 1982. Recherches sur l'écologie des "récifs" d’hermelles édifiés par l'Annélide Polychète Sabellaria alveolata (Linné). (Thèse Doctorat d'Etat). Nantes.

Gruet, Y., 1986. Spatio-temporal Changes of Sabellarian Reefs Built by the Sedentary Polychaete Sabellaria alveolata (Linné). Marine Ecology 7, 303-319. doi:10.1111/j.1439-0485.1986.tb00166.x

Haas, A.F., Guibert, M., Foerschner, A., Co, T., Calhoun, S., George, E., Hatay, M., Dinsdale, E., Sandin, S.A., Smith, J.E., Vermeij, M.J.A., Felts, B., Dustan, P., Salamon, P., Rohwer, F., 2015. Can we measure beauty? Computational evaluation of coral reef aesthetics. PeerJ 3, e1390. https://doi.org/10.7717/peerj.1390

Hattam, C., Atkins, J.P., Beaumont, N., Börger, T., Böhnke-Henrichs, A., Burdon, D., Groot, R. de, Hoefnagel, E., Nunes, P.A.L.D., Piwowarczyk, J., Sastre, S., Austen, M.C., 2015. Marine ecosystem services: Linking indicators to their classification. Ecological Indicators 49, 61-75. https://doi.org/10.1016/j.ecolind.2014.09.026

Hazel, J.R., 1995. Thermal Adaptation in Biological Membranes: Is Homeoviscous Adaptation the Explanation? Annual Review of Physiology 57, 19-42. https://doi.org/10.1146/annurev.ph.57.030195.000315

Hazel, J.R, Williams, E.E., 1990. The role of alterations in membrane lipid composition in enabling physiological adaptation of organisms to their physical environment. Progress in Lipid Research 29, 167-227. https://doi.org/10.1016/0163-7827(90)90002-3

Helmuth, B., Harley, C.D.G., Halpin, P.M., O’Donnell, M., Hofmann, G.E., Blanchette, C.A., 2002. Climate Change and Latitudinal Patterns of Intertidal Thermal Stress. Science 298, 1015-1017. https://doi.org/10.1126/science.1076814

Hendrick, V.J., Foster-Smith, R.L., 2006. Sabellaria spinulosa reef: a scoring system for evaluating 'reefiness' in the context of the Habitats Directive. Journal of the Marine Biological Association of the UK 86, 665. doi:10.1017/S0025315406013555

Hentschel, B.T., 1998. Spectrofluorometric quantification of neutral and polar lipids suggests a food-related recruitment bottleneck for juveniles of a deposit-feeding polychaete population. Limnology and Oceanography 43, 543-549. https://doi.org/10.4319/1o.1998.43.3.0543

Hochachka, P.W., Somero, G.N., 2002. Biochemical adaptation: mechanism and process in physiological evolution. Oxford University Press, New York.

Holt, T.J., Rees, E.I., Hawkins, S.J., Seed, R., 1998. Biogenic Reefs. An overview of dynamic and sensitivity characteristics for conservation management of marine SACs. (No. volume IX). Scottish Association for Marine Science (UK Marine SACs Project).

Hulbert, A.J., Turner, N., Storlien, L.H., Else, P.L., 2005. Dietary fats and membrane function: implications for metabolism and disease. Biological Reviews 80, 155-169. https://doi.org/10.1017/S1464793104006578

Johnson, C.R., 2009. Natural Length Scales of Ecological Systems: Applications at Community and Ecosystem Levels. Ecology and Society 14. doi:10.5751/ES-02749140107

Jones, A.G., Dubois, S.F., Desroy, N., Fournier, J., 2018. Interplay between abiotic factors and species assemblages mediated by the ecosystem engineer Sabellaria alveolata (Annelida: Polychaeta). Estuarine, Coastal and Shelf Science 200, 1-18. doi:10.1016/j.ecss.2017.10.001 
Le Foll, C., Corporeau, C., Le Guen, V., Gouygou, J.-P., Berge, J.-P., Delarue, J., 2006. Long-chain n-3 polyunsaturated fatty acids dissociate phosphorylation of Akt from phosphatidylinositol 3'-kinase activity in rats. AJP: Endocrinology and Metabolism 292, E1223-E1230. https://doi.org/10.1152/ajpendo.00446.2006

Lefebvre, S., Marín Leal, J.C., Dubois, S., Orvain, F., Blin, J.-L., Bataillé, M.-P., Ourry, A., Galois, R., 2009. Seasonal dynamics of trophic relationships among co-occurring suspension-feeders in two shellfish culture dominated ecosystems. Estuarine, Coastal and Shelf Science 82, 415-425. https://doi.org/10.1016/j.ecss.2009.02.002

Lesser, M.P., 2006. Oxidative Stress in Marine Environments: Biochemistry and Physiological Ecology. Annual Review of Physiology 68, 253-278. https://doi.org/10.1146/annurev.physiol.68.040104.110001

Levoy, F., Anthony, E.J., Monfort, O., Larsonneur, C., 2000. The morphodynamics of megatidal beaches in Normandy, France. Marine Geology 171, 39-59. https://doi.org/10.1016/S0025-3227(00)00110-9

Lochmiller, R.L., Deerenberg, C., 2000. Trade-offs in evolutionary immunology: just what is the cost of immunity? Oikos 88, 87-98. https://doi.org/10.1034/j.1600$\underline{0706.2000 .880110 . x}$

Lourenço, S., Roura, Á., Fernández-Reiriz, M.-J., Narciso, L., González, Á.F., 2017. Feeding Relationship between Octopus vulgaris (Cuvier, 1797) Early Life-Cycle Stages and Their Prey in the Western Iberian Upwelling System: Correlation of Reciprocal Lipid and Fatty Acid Contents. Frontiers in Physiology 8. https://doi.org/10.3389/fphys.2017.00467

Lowry, O. H., Rosebrough, N. J., Farr, A. L. and Randall, R. J., 1951. Protein measurement with the Folin phenol reagent. The Journal of Biological Chemistry 193, 265-75.

Lucas, A., Beninger, P.G., 1985. The use of physiological condition indices in marine bivalve aquaculture. Aquaculture 44, 187-200. https://doi.org/10.1016/0044-8486(85)90243-1

Marty, Y., Delaunay, F., Moal, J., Samain, J.-F., 1992. Changes in the fatty acid composition of Pecten maximus (L.) during larval development. Journal of Experimental Marine Biology and Ecology 163, 221-234. https://doi.org/10.1016/0022-0981(92)90051-B

Masuda, R., 2003. The critical role of docosahexaenoic acid in marine and terrestrial ecosystems: from bacteria to human behavior, in: The Big Fish Bang. Proceedings of the 26th Annual Larval Fish Conference. Howard I. Browman \& Anne Berit Skiftesvik, Os, Norway, pp. 249-256.

Metcalfe, L.D., Schmitz, A.A., 1961. The Rapid Preparation of Fatty Acid Esters for Gas Chromatographic Analysis. Analytical Chemistry 33, 363-364. https://doi.org/10.1021/ac60171a016

Miller, D.C., Geider, R.J. and MacIntyre, H.L., 1996. Microphytobenthos: the ecological role of the "secret garden" of unvegetated, shallow-water marine habitats. II. Role in sediment stability and shallow-water food webs. Estuaries, 19(2), 202-212.

Morrison, W. R. and Smith, L. M., 1964. Preparation of fatty acid methyl esters and dimethylacetals from lipids with boron fluoride-methanol. Journal of Lipid Research 5, 600-8.

Moyes, C.D., 2003. Controlling muscle mitochondrial content. Journal of Experimental Biology 206, 4385-4391. https://doi.org/10.1242/jeb.00699 
Muir, A.P., Nunes, F.L.D., Dubois, S.F., Pernet, F., 2016. Lipid remodelling in the reefbuilding honeycomb worm, Sabellaria alveolata, reflects acclimation and local adaptation to temperature. Scientific Reports 6, 35669. doi:10.1038/srep35669

Osada, M., Nishikawa, M., Nomura, T., 1989. Involvement of prostaglandins in the spawning of the scallop, Patinopecten yessoensis. Comparative Biochemistry and Physiology. C: Comparative Pharmacology 94, 595-601.

Pawlik, J.R., 1986. Chemical induction of larval settlement and metamorphosis in the reefbuilding tube worm Phragmatopoma californica (Sabellariidae: Polychaeta). Marine Biology 91, 59-68. https://doi.org/10.1007/BF00397571

Pernet, F., Lagarde, F., Jeannée, N., Daigle, G., Barret, J., Le Gall, P., Quere, C., D’orbcastel, E.R., 2014. Spatial and Temporal Dynamics of Mass Mortalities in Oysters Is Influenced by Energetic Reserves and Food Quality. PLoS ONE 9, e88469. https://doi.org/10.1371/journal.pone.0088469

Pernet, F., Tremblay, R., Comeau, L., Guderley, H., 2007. Temperature adaptation in two bivalve species from different thermal habitats: energetics and remodelling of membrane lipids. Journal of Experimental Biology 210, 2999-3014. https://doi.org/10.1242/jeb.006007

Pernet, B., Jaeckle, W.B., 2004. Size and Organic Content of Eggs of Marine Annelids, and the Underestimation of Egg Energy Content by Dichromate Oxidation. The Biological Bulletin 207, 67-71. https://doi.org/10.2307/1543629

Plicanti, A., Domínguez, R., Dubois, S.F., Bertocci, I., 2016. Human impacts on biogenic habitats: Effects of experimental trampling on Sabellaria alveolata (Linnaeus, 1767) reefs. Journal of Experimental Marine Biology and Ecology 478, 34-44. https://doi.org/10.1016/j.jembe.2016.02.001

Porras, R., Bataller, J.V., Murgui, E., Torregrosa, M.T., 1996. Trophic Structure and Community Composition of Polychaetes Inhabiting Some Sabellaria alveolata (L.) Reefs Along the Valencia Gulf Coast, Western Mediterranean. Marine Ecology 17, 583-602. https://doi.org/10.1111/j.1439-0485.1996.tb00419.x

Rivest, E.B., Chen, C.-S., Fan, T.-Y., Li, H.-H., Hofmann, G.E., 2017. Lipid consumption in coral larvae differs among sites: a consideration of environmental history in a global ocean change scenario. Proceedings of the Royal Society B: Biological Sciences 284, 20162825. https://doi.org/10.1098/rspb.2016.2825

Rivest, E.B., Hofmann, G.E., 2014. Responses of the Metabolism of the Larvae of Pocillopora damicornis to Ocean Acidification and Warming. PLoS ONE 9, e96172. https://doi.org/10.1371/journal.pone.0096172

Scheer, B.T., 1969. Carbohydrates and carbohydrate metabolism: Annelida, Sipuncula, Echiura. Chemical zoology, 4.

Schimmenti, E., Musco, L., Lo Brutto S., Mikac, B., Nygren, A., Badalamenti, F., 2015 « A Mediterranean Record of Eulalia Ornata (Annelida: Phyllodocidae) Corroborating Its Fidelity Link with the Sabellaria Alveolata-Reef Habitat ». Mediterranean Marine Science 17(2): 359-70. 
Soudant, P., Van Ryckeghem, K., Marty, Y., Moal, J., Samain, J.F., Sorgeloos, P., 1999. Comparison of the lipid class and fatty acid composition between a reproductive cycle in nature and a standard hatchery conditioning of the Pacific Oyster Crassostrea gigas. Comparative Biochemistry and Physiology Part B: Biochemistry and Molecular Biology 123, 209-222. https://doi.org/10.1016/S0305-0491(99)00063-2

Tessier, B., 1993. Upper intertidal rhythmites in the Mont-Saint-Michel Bay (NW France): perspectives for paleoreconstruction. Marine Geology 110, 355-367.

Tremblay, R., Olivier, F., Bourget, E., Rittschof, D., 2007. Physiological condition of Balanus amphitrite cyprid larvae determines habitat selection success. Marine Ecology Progress Series 340, 1-8.

Wilson, D. 1968. The settlement behaviour of the larvae of Sabellaria alveolata (L.). Journal of the Marine Biological Association of the United Kingdom, 50, 1-45.

Wilson, D.P., 1971. Sabellaria Colonies At Duckpool, North Cornwall, 1961-1970. Journal of the Marine Biological Association of the United Kingdom 51, 509. https://doi.org/10.1017/S002531540001496X

Winder, M., Carstensen, J., Galloway, A.W.E., Jakobsen, H.H., Cloern, J.E., 2017. The landsea interface: A source of high-quality phytoplankton to support secondary production: Nutritious phytoplankton support coastal systems. Limnology and Oceanography 62, S258-S271. https://doi.org/10.1002/lno.10650

\section{Figure legends}

Figure 1 Conceptual diagram of a) the different bioconstruction Types of $S$. alveolata (adapted from Gruet, 1986). Progradation and Retrogradation, as defined in b), are represented by full versus hatched arrows respectively. Note that a bioconstruction can cycle between the two Phases - as represented by the circular arrows - within the same bioconstruction Type. Images (C) Ifremer.

Figure 2 Map of the study site with the twelve sampling points. V=Veneer, $H R=$ Retrograding Hummock, HPHs=Prograding Hummock High Shore, HPLs=Prograding Hummock Low Shore. 
892

893

894

895

896

897

898

899

900

901

902

903

904

905

906

907

908

909

910

911

912

913

914

Figure 3 Organic macromolecules in the honeycomb worm Sabellaria alveolata as a function of bioconstruction type, bioconstruction phase and shore level (a-c, n=59), worm mass (d-f, $\mathrm{n}=59$ ) and sex (g-i $\mathrm{n}=8$ (5 female, 3 male $))$. All y axis units are $\mathrm{mg} \cdot \mathrm{g}^{-1}$ tissue. $\mathrm{V}=\mathrm{Veneer}$, $\mathrm{H}=$ Hummock, HR=Retrograding Hummock, HP=Prograding Hummock, HPHs=Prograding Hummock High shore, HPLs=Prograding Hummock Low shore. Carbohydrate statistical test results are log-transformed. The letters "a" and "b" represent a significant difference in the contrast test $(\mathrm{p}=0.002) . * \mathrm{p} \leq 0.05$.

Figure 4 Polar lipids in the honeycomb worm Sabellaria alveolata as a function of bioconstruction type, bioconstruction phase and shore level (a-d, n=59), worm mass (e-h, $\mathrm{n}=59$ ) and sex (i-1, $\mathrm{n}=8$ (5 female, 3 male)). All y axis units are a percentage of total phospholipids. Note that the y axis scale varies between fatty acids. $V=$ Veneer, $\mathrm{H}=\mathrm{Hummock}$, HR=Retrograding Hummock, HP=Prograding Hummock, HPHs=Prograding Hummock High shore, HPLs=Prograding Hummock Low shore. 22:6n-3 statistical test results are logtransformed. The letters "a" and "b" represent a significant difference in the bioconstruction type contrast test $(\mathrm{p}=0.009)$, and the letters "c" and " $\mathrm{d}$ " in the bioconstruction type contrast test $(\mathrm{p}=0.024) . *=\mathrm{p} \leq 0.05$.

Figure 5 Neutral lipids in the honeycomb worm Sabellaria alveolata as a function of bioconstruction type, bioconstruction phase and shore level (a-f, $\mathrm{n}=59)$, worm mass ( $\mathrm{g}-\mathrm{k}$, $\mathrm{n}=59)$ and sex (m-r, n=8 (5 female, 3 male $))$. All y axis units are a percentage of total neutral lipids. Note that the $y$ axis scale varies between fatty acids. Diatoms=16:1n-7/16:0; Dinoflagellates=22:6n-3/20:5n-3; Carnivory=18:1n-9/18:1n-7; Bacterial $=15: 0+17: 0+$ 
915 branched fatty acids; Terrestrial $=18: 2 n-6+18: 3 n-3 ;$ Freshness $=$ PUFA/SFA. V=Veneer,

$916 \mathrm{H}=$ Hummock, HR=Retrograding Hummock, HP=Prograding Hummock, HPHs=Prograding

917 Hummock High shore, HPLs=Prograding Hummock Low shore. $*=p \leq 0.05$

918 Figure 6 Enzyme levels in the honeycomb worm Sabellaria alveolata as a function of 919 bioconstruction type, bioconstruction phase and shore level (a-c, n=59), worm mass (d-f, $920 \mathrm{n}=59)$ and sex $(\mathrm{g}-\mathrm{I}, \mathrm{n}=8$ (5 female, 3 male $))$. CS y axis units are micro Units $\left.\mathrm{mU} \cdot \mathrm{mg}^{-1}\right)$ of 921 protein, whereas CAT and SOD units are $\mathrm{U}_{\mathrm{mg}}{ }^{-1}$ of protein. $\mathrm{CS}=$ Citrate synthase, 922 CAT=Catalase, $\mathrm{SOD}=$ Superoxide dismutase. V=Veneer, H=Hummock, HR=Retrograding 923 Hummock, HP=Prograding Hummock, HPHs=Prograding Hummock High shore, 924 HPLs=Prograding Hummock Low shore. All statistical test results are log-transformed. The 925 letters "a" and " $b$ " represent a significant difference in the contrast test $(\mathrm{p}=0.013) . *=\mathrm{p} \leq 0.05$. 
a)

Hummock Type
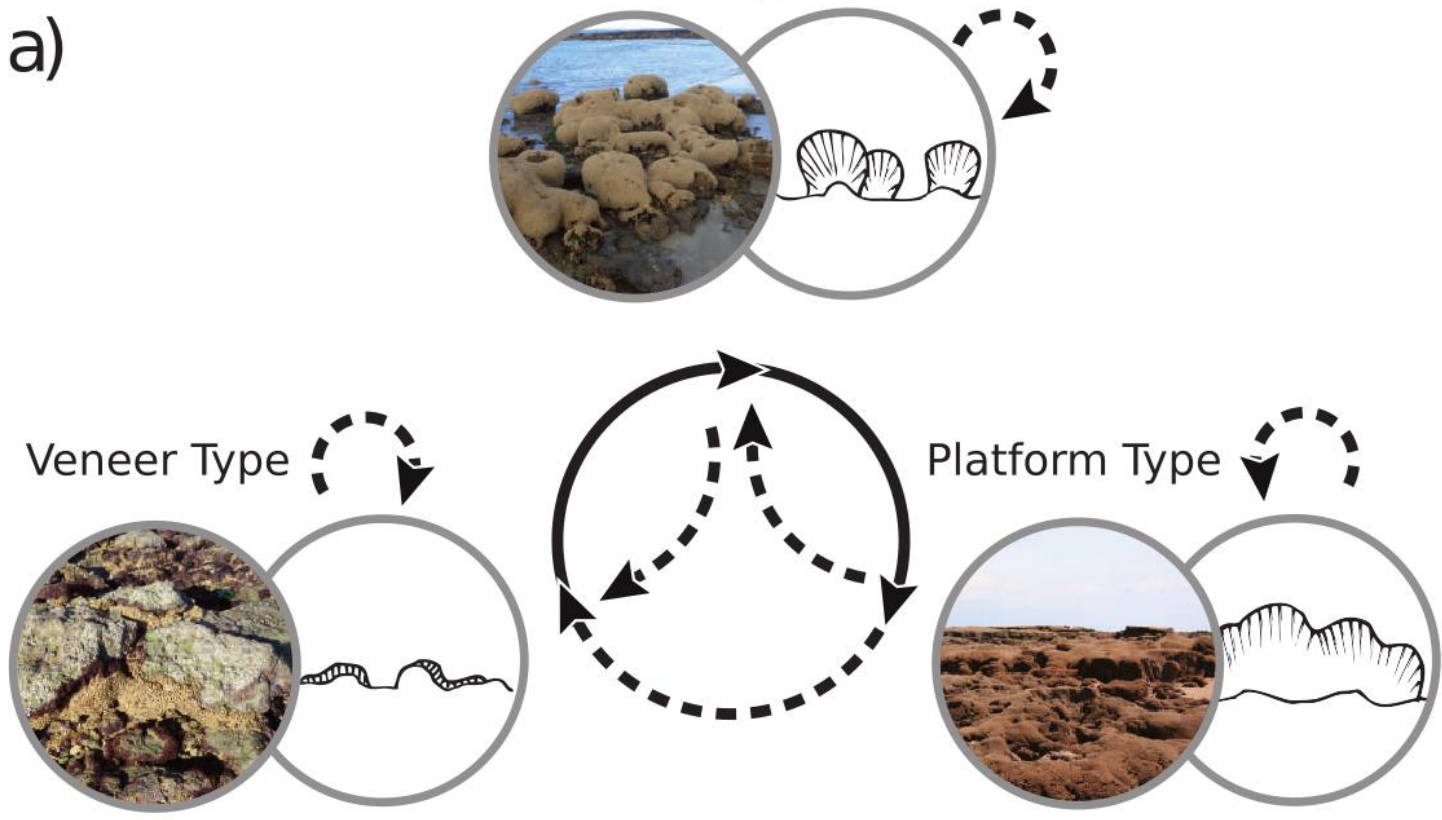

b)

Progradation Phase

- Dominated by occupied tubes identified by porches

- Limited/No epibionts

- Uniform aspect

-Presence of small tube openings (aperture $<2.5 \mathrm{~mm}$ ) indicating recruitment

- Surface of reef of similar colour to surrounding sediment

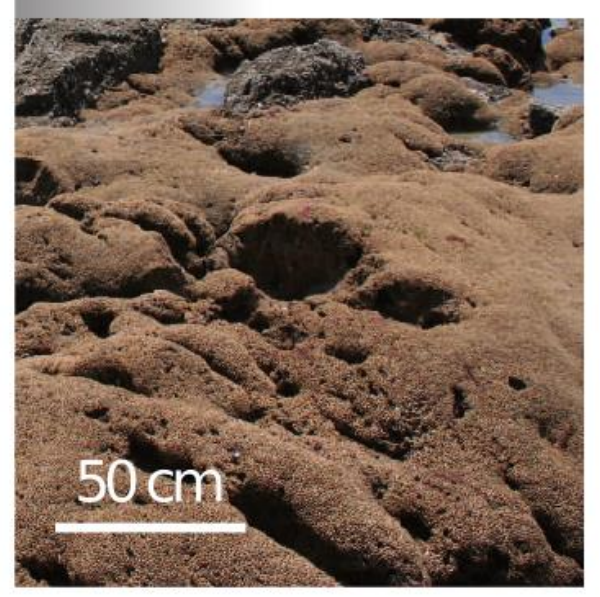

Retrogradation Phase

-Mosaic of occupied and unoccupied tubes (identified by lack of porches)

- Often featuring epibionts/biofilms

-Signs of reef erosion

- No visible small tube openings (aperture $<2.5 \mathrm{~mm}$ )

-Surface of reef highly fragmented and dark brown to grey in colouration

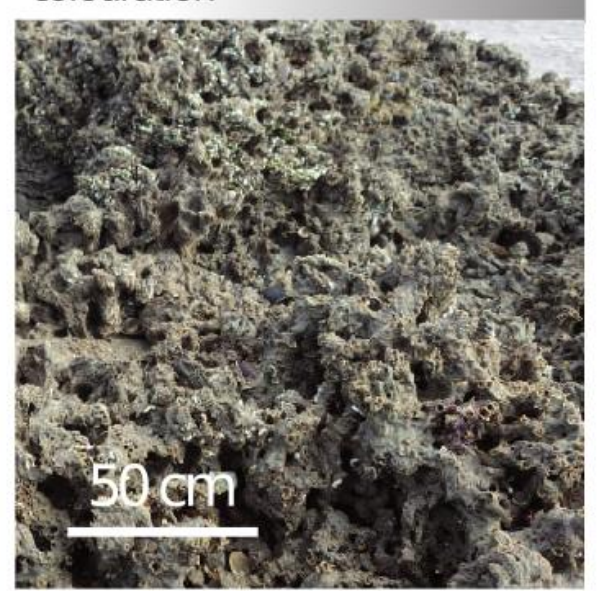


Figure 2

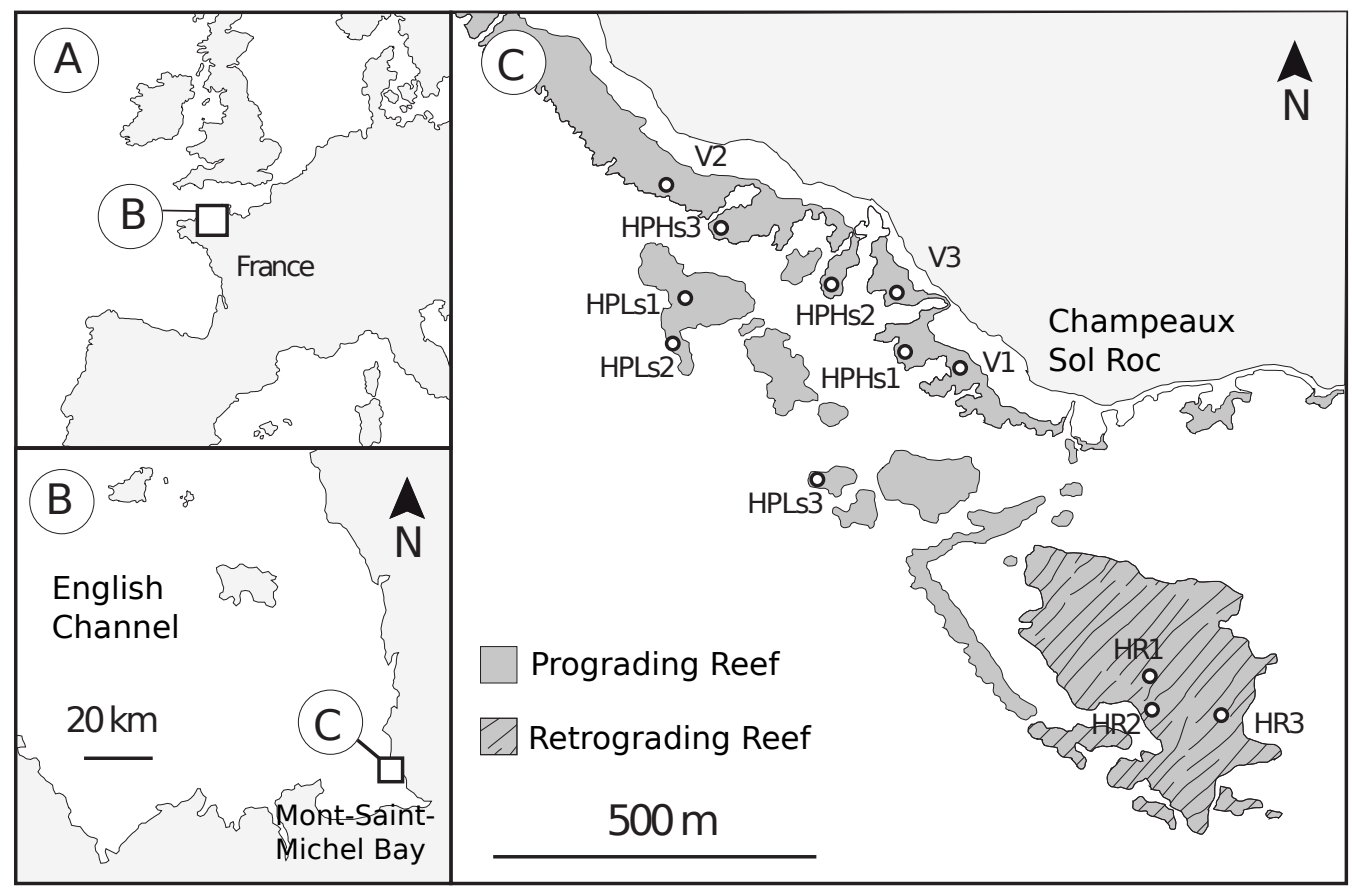


Figqre $\mathbb{B}=1.1 \quad p=0.395$

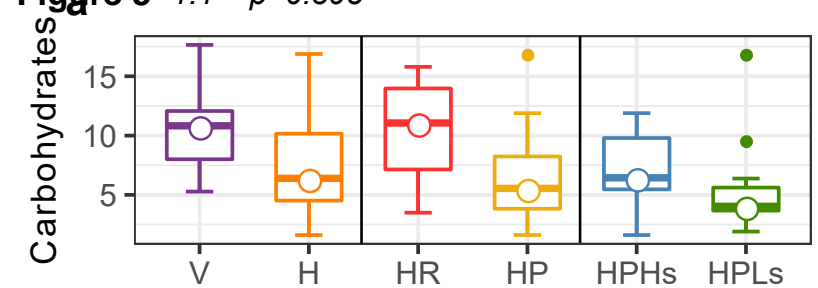

b $\quad F=0.3 \quad p=0.799$

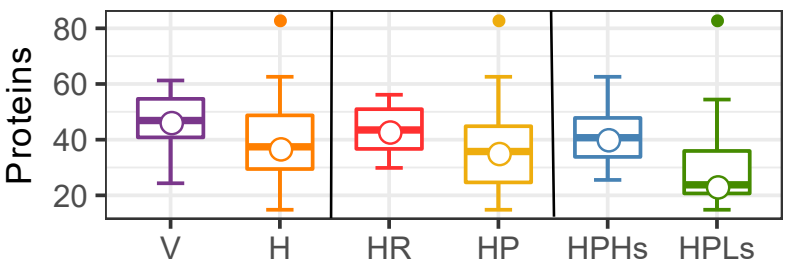

C $F=8.0 p=0.009^{*}$

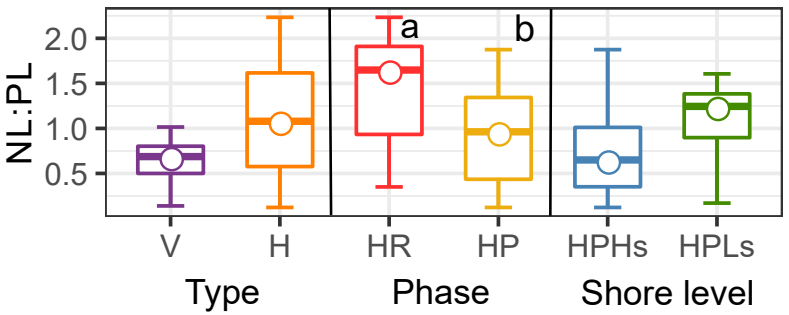

d $F=21.2 p<0.001^{*}$

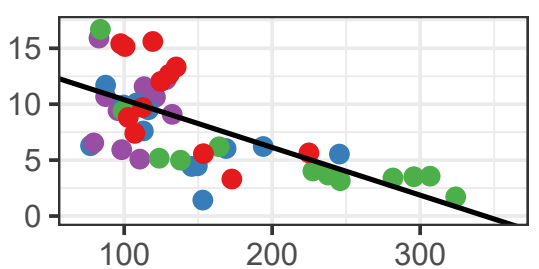

e $F=52.7 \quad p<0.001^{*}$

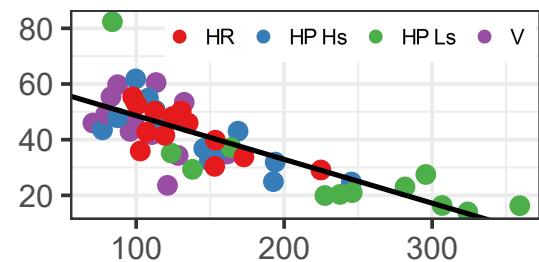

f $F=9.9 p=0.003^{*}$

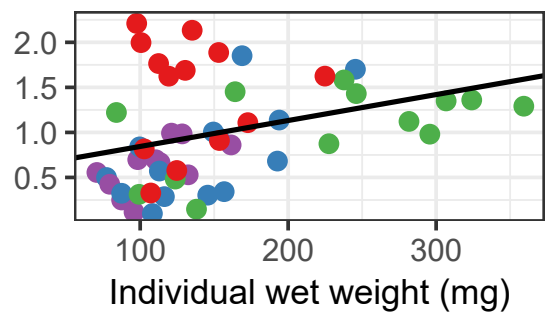

g

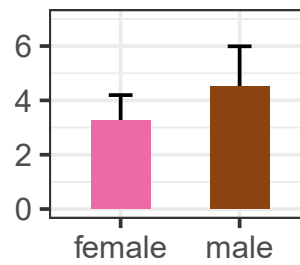

h

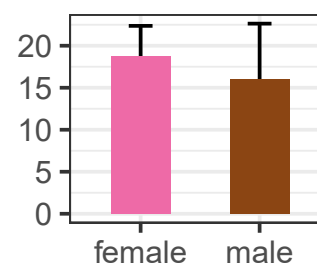

i

$F=14.3 \quad p<0.001^{*}$

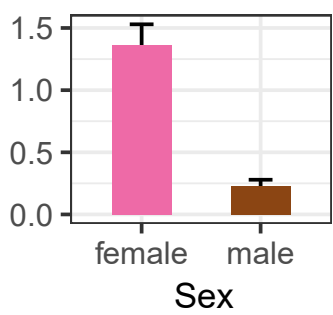


Figure $5 F=2.2 \quad p=0.170$

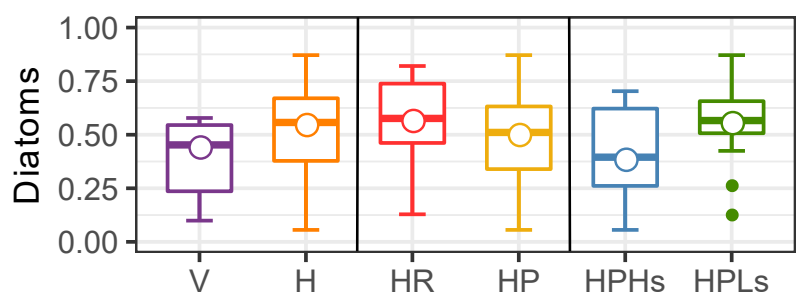

b $\quad F=1.5 p=0.289$

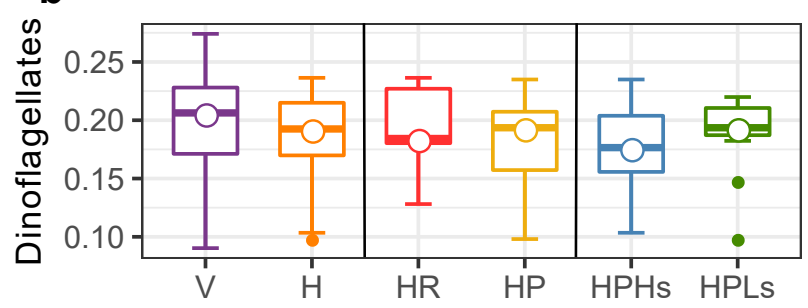

C $F=1.8 p=0.225$

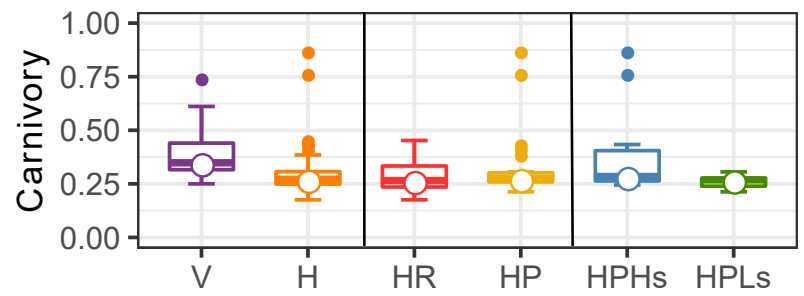

d $\quad F=1.0 \quad p=0.456$

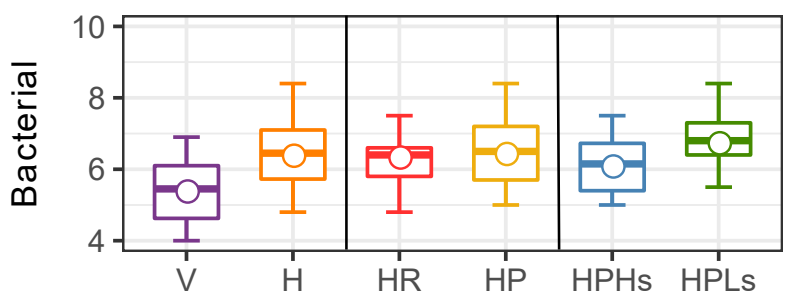

e $F=2.2 p=0.170$

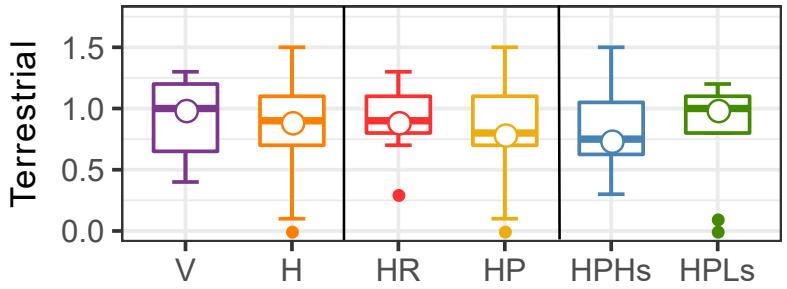

f $\quad F=1.1 \quad p=0.399$

क

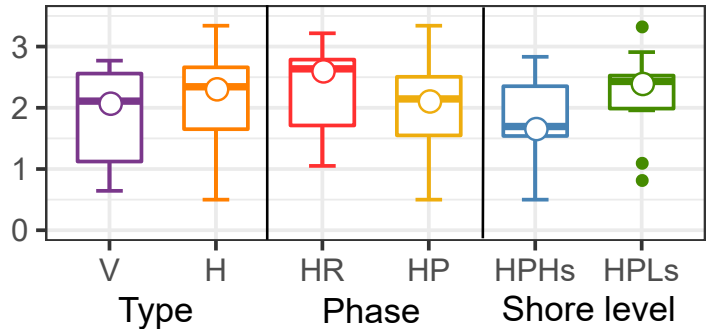

g

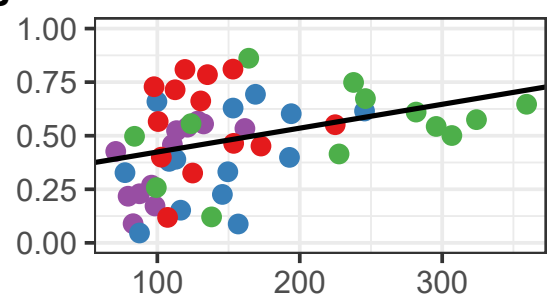

h

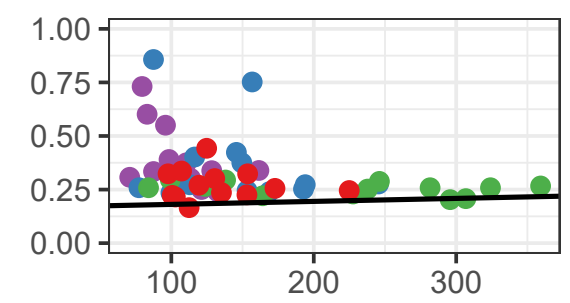

i $\quad F=2.0 \quad p=0.162$

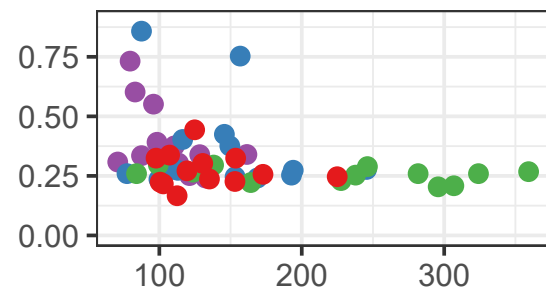

j

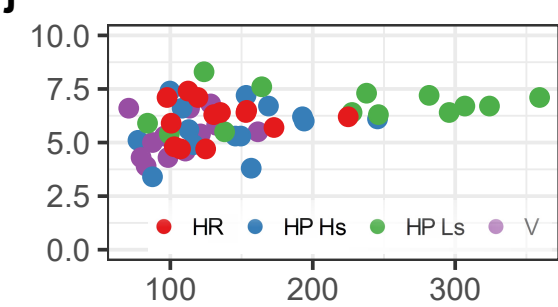

k $\quad F=7.9 p=0.008^{*}$

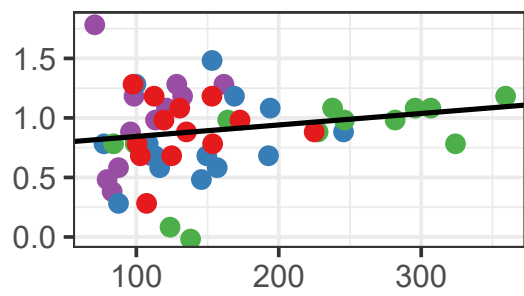

I $F=4.1 p=0.050^{*}$

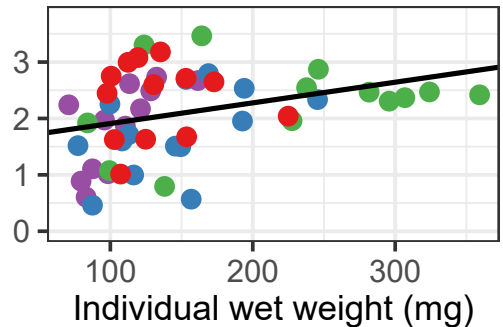

$m$

$F=5.7 \quad p<0.001^{*}$

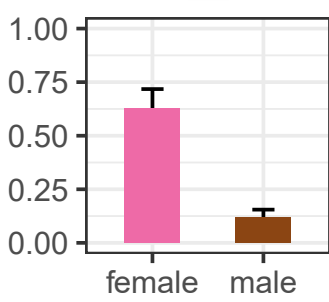

n $F=2.7 p=0.013^{*}$

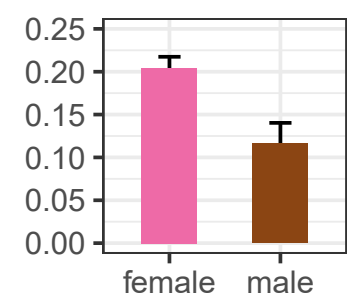

0

$F=2.2 p=0.024^{*}$

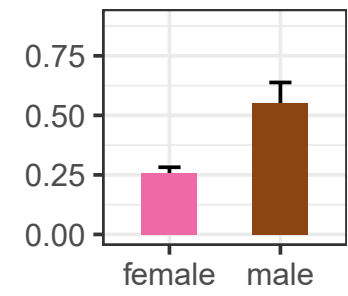

p

$F=3.4 p=0.001^{*}$

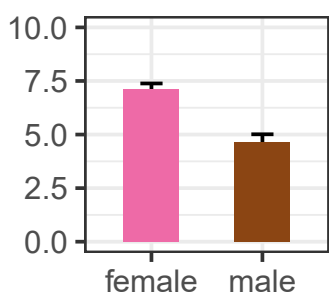

q

$F=5.5 \quad p<0.001^{*}$

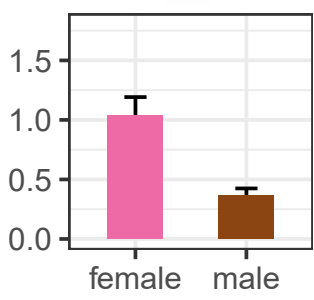

r $F=2.3 p=0.003^{*}$

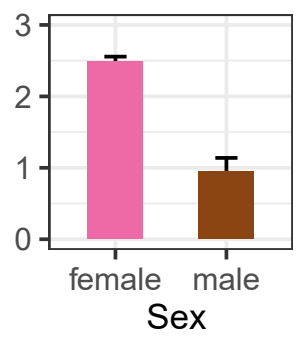


Figure66.4 $p=0.016^{*}$

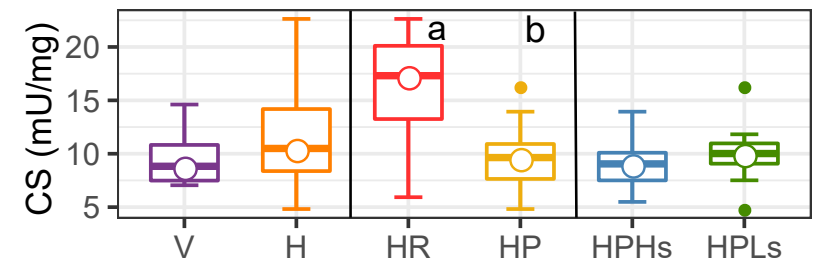

b $F=3.1 \quad p=0.092$

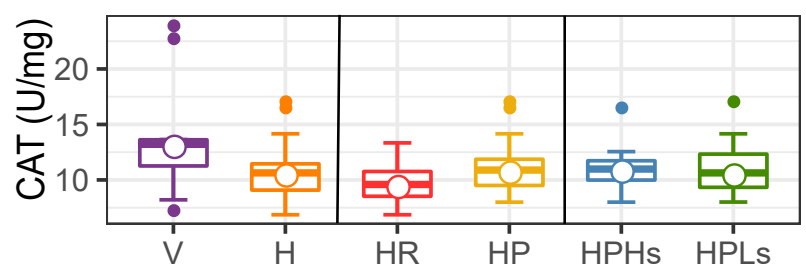

C $F=3.0 p=0.097$

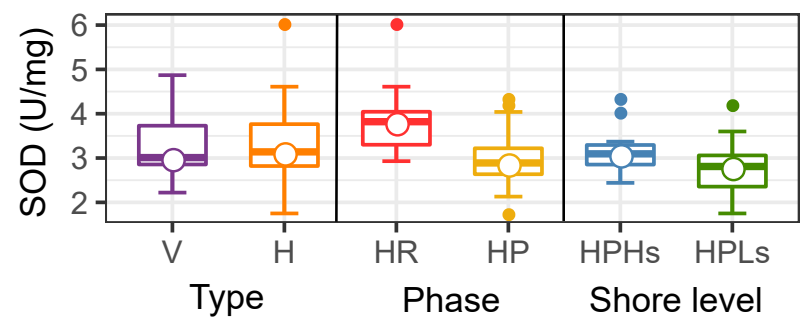

d $F=7.5 p=0.009^{*}$

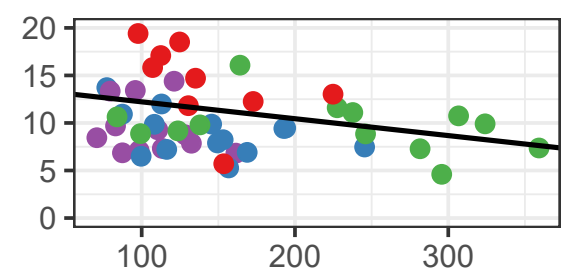

e $F=0.8 p=0.375$

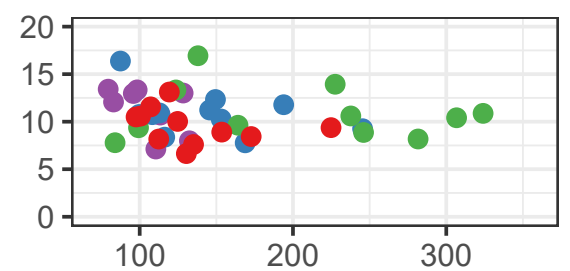

f $F=1.0 \quad p=0.335$

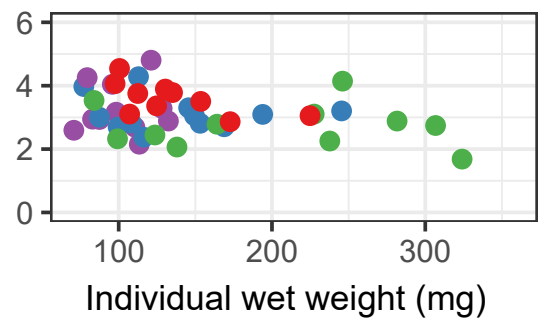

g

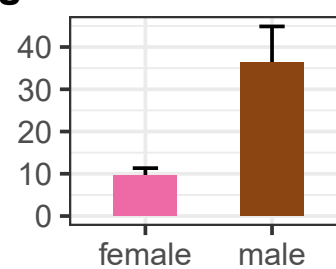

h $F=2.3 p=0.251$

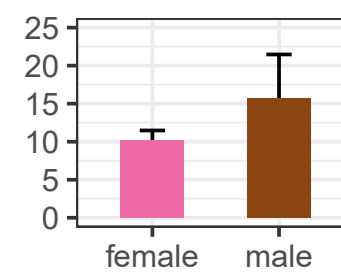

i $F=3.9 p=0.165$

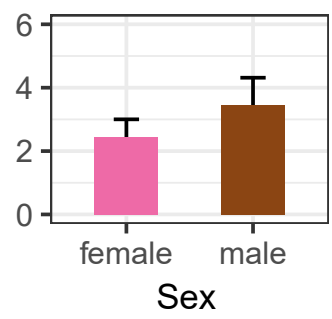


S1_PCA
Click here to download Supplementary Material: File_S1_PCA.pdf Click here to download Supplementary Material: File_S1_PCA.pdf

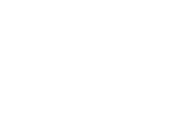

$\sqrt{2}$ (1) (1) (1) $\sqrt{3}$ (1) (1) (1)

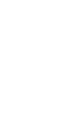

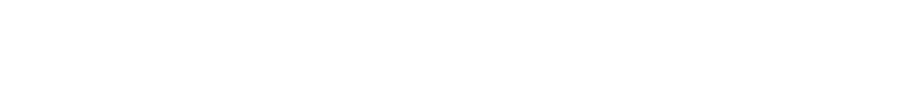
(1) . (1) (1) (1) (1)

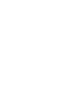
(1) (1)

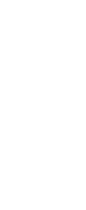
. .

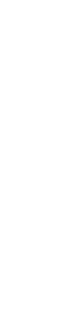

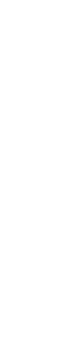

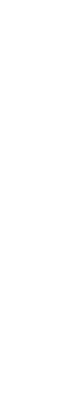
列

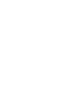

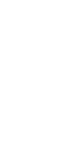

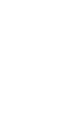

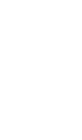

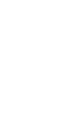

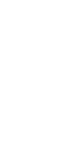
(

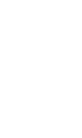

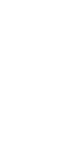

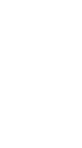

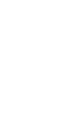




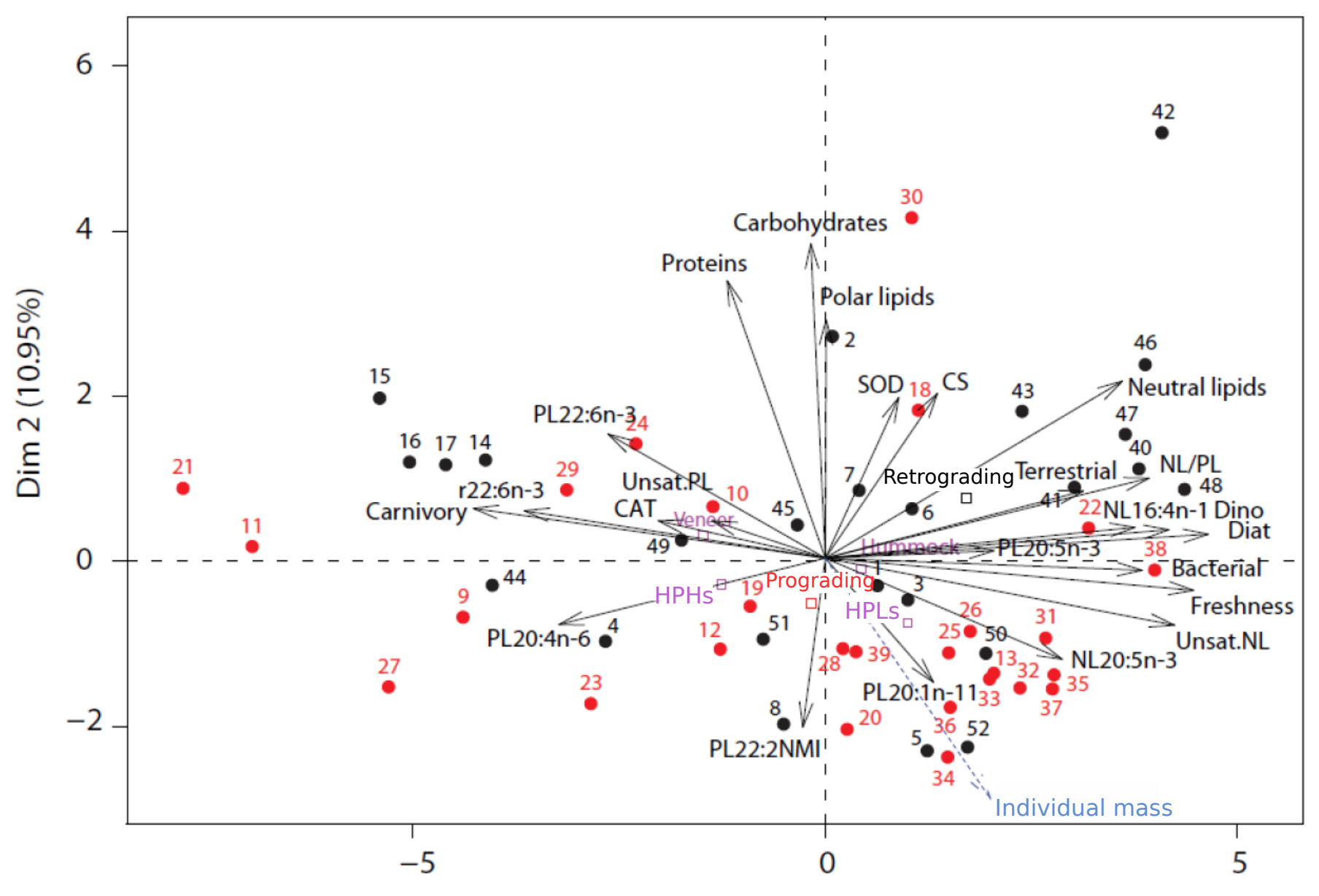

$\operatorname{Dim} 1(38.73 \%)$

Principal Component Analysis (PCA) biplot of 52 female Sabellaria alveolata individuals and 26 biochemical variables. Individual mass is considered as an illustrative quantitative variable, and reef type and phase are considered as illustrative qualitative variables. The first two dimensions of the PCA express $49.68 \%$ of the total dataset inertia. Individuals are coloured after their category for the variable "Reef Phase": progradation phase individuals are in red, retrogradation phase individuals are in black. PCA calculated using the PCA function of the package FactoMineR (Lê et al., 2008).

Lê, S., Josse, J. \& Husson, F. (2008). FactoMineR: An R Package for Multivariate Analysis. Journal of Statistical Software. 25(1). pp. 1-18 